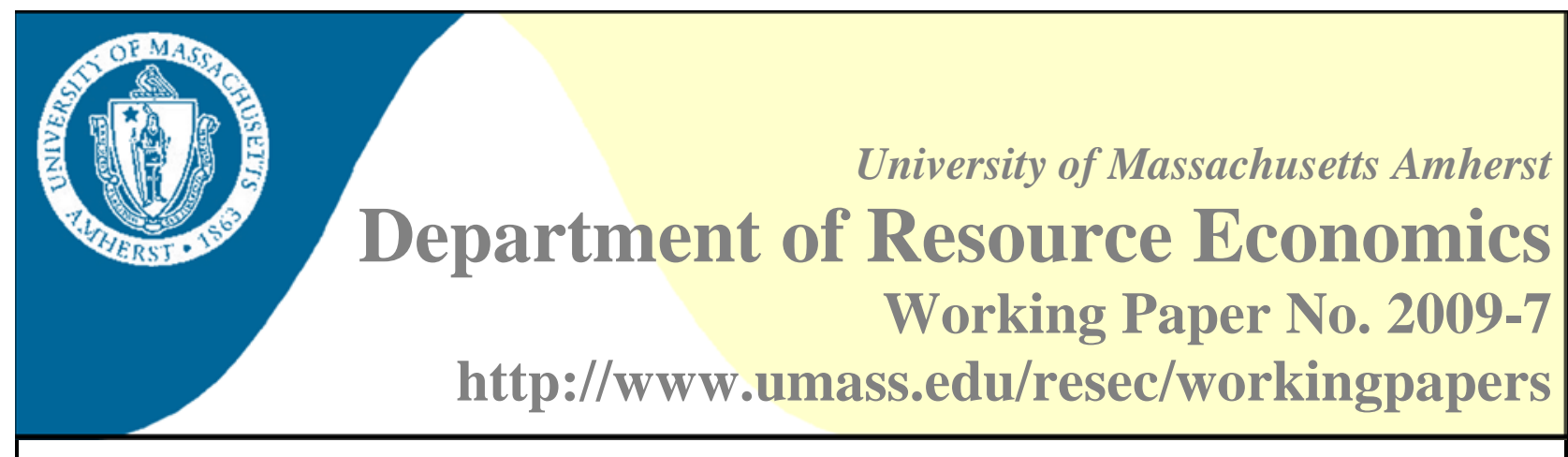

\title{
Partial Implementation of COOL: Economic Effects in the U.S. Seafood Industry
}

\author{
Siny Joseph ${ }^{1}$, Nathalie Lavoie ${ }^{2}$, and Julie A. Caswell ${ }^{3}$
}

Abstract:

Mandatory Country of Origin Labeling (MCOOL) was implemented on seafood in the United States on April 4, 2005. MCOOL exempts the foodservice sector and excludes processed seafood from labeling. This paper contributes to understanding the economics of the MCOOL law for seafood by showing that current partial implementation may have unintended consequences on the domestic supply chain. While labeling satisfies the market demand for information provision in one market, exemptions in the other market may create incentives for the diversion of imports, which are assumed to be lower in quality than domestic seafood, to the non-labeled sector. Analyzing alternate scenarios such as voluntary labeling shows that total welfare may be greatest under this scenario compared with partial MCOOL. Voluntary origin labeling of seafood by some U.S. retailers indicates there is no compelling market failure argument warranting partial MCOOL implementation. This work is therefore a step towards analyzing the effect of partial MCOOL policy in the seafood industry taking into consideration the nature of the industry.

Keywords: Country of origin labeling, product differentiation, information asymmetry, seafood JEL Classification: L15, L22, Q18

\footnotetext{
${ }^{1}$ Siny Joseph, Department of Resource Economics

University of Massachusetts, Stockbridge Hall

80 Campus Center Way, Amherst, MA 01003-9246

E: siny@resecon.umass.edu P: 316-350-4666 F: 413-545-5853

${ }^{2}$ Nathalie Lavoie, Department of Resource Economics

University of Massachusetts, 212D Stockbridge Hall

80 Campus Center Way, Amherst, MA 01003-9246

E: lavoie@resecon.umass.edu P: 413-545-5713 F: 413-545-5853

${ }^{3}$ Julie A. Caswell, Department of Resource Economics

University of Massachusetts, 215 Stockbridge Hall

80 Campus Center Way, Amherst, MA 01003-9246

E: caswell@resecon.umass.edu P: 413-545-5735 F: 413-545-5853
} 


\section{Partial Implementation of COOL: Economic Effects in the U.S. Seafood Industry}

\section{Introduction}

The recent spate of incidents with U.S. imports has turned the heat back on the issue of mandatory country-of-origin labeling (MCOOL). Prominent incidents are recalls of a number of Chinese-made products: farm-raised shrimp and catfish, pet food laced with contaminated wheat gluten, toothpaste containing diethylene glycol-a poison used in antifreeze, children's necklaces and earrings, toy trains and popular preschool toys containing high levels of lead. Barboza (2007) outlines the degraded conditions in which some seafood for export to United States is farmed in China. The media also reports that at-risk Chinese seafood shipments that are supposed to be tested for safety are going unchecked and that FDA personnel "inspect less than 1 percent of all imported food and conduct laboratory analysis on only a tiny fraction of those (LA Times, 2007; www.foodandwaterwatch.org).”

At the same time, a food labeling poll conducted by Consumer Reports shows that consumers want to know where their food comes from and expect higher label standards. According to the poll, 92 percent of consumers agree that imported foods should be labeled by their country of origin.

The U.S. Congress implemented MCOOL in the United States in April 2005 for fish and shellfish. The objective was to communicate to consumers the national origin and method of production (wild or farm-raised) via mandatory labels. However, the labels are restricted to fresh and frozen seafood at the retail level. Foodservice establishments, small retailers and ingredients in processed seafood products are exempt. 
On one hand, the resulting partial coverage creates a potentially gaping hole possibly undermining the effectiveness of MCOOL law. On the other hand, is there a market failure that warrants the implementation of this law? This paper tackles these issues.

The increase in demand for fish and seafood, the growth of cheaper imports of seafood and particularly the increase in consumption away-from-home, and the partial implementation of MCOOL imply that a large part of the market is not covered by the law. According to Hale (2005), restaurants are the key source of seafood, with 60 percent of consumers reporting they eat more seafood away from home. More specifically Keithly (1985) estimates that the quantity of away-from-home seafood products consumed ranges from one-third to two-thirds of all consumption of seafood. The overall exempt market (retailers not subject to the rule and foodservice establishments) accounts for 62 percent of fish and 75 percent of shellfish (USDA-AMS, 2004). Stewart et al. (2004) predict that per capita spending on seafood could rise by 18 percent at full-service restaurants and by 6 percent for fast food between 2000 and 2020 .

Currently, over 70 percent of the seafood Americans consume is imported (National Marine Fisheries Service, 2007). The significant share of imports in U.S. seafood consumption raises concern about their safety. In the United States, the use of the Hazard Analysis Critical Control Points (HACCP) system is considered necessary to ensure quality and safety of seafood. While imports are required to have the same standards of quality and safety, enforcement may be weaker. HACCP operates in the context of an extensive set of requirements for good manufacturing practices and sanitary operating procedures. In addition, there are numerous federal and state regulations that influence the location and timing of harvest and the choices of aquaculture operations 
(Caswell, 2006). Products from less developed countries are generally perceived to be of lower quality than products of developed countries (Verlegh and Steenkamp, 1999). According to the U.S. Department of Commerce, 80 percent of the total imported edible seafood in 2007 came from less developed countries. Although there is no evidence that imported seafood is necessarily riskier, a number of countries exporting seafood to the United States have poorer internal control systems and/or are in tropical areas where toxin and bacteria hazards are higher. Imports become an issue of concern because countries vary in their use of vaccines, feed additives, and antibiotics for farm-raised fish and shellfish (Allshouse et al., 2004).

The objective of this paper is to examine the welfare effects for consumers and sellers with MCOOL implementation for seafood, given that more than 70 percent of seafood consumed in the United States is imported and most of it (by value) is consumed in the foodservice sector. MCOOL is a retail labeling program and does not cover the foodservice sector. As noted above, exemptions and exclusions of MCOOL on covered seafood products amount to 62 percent fish and 75 percent of shellfish. This effectively means that most of the imported seafood consumed in United States is not affected by the MCOOL legislation. The presence of a non-labeled sector raises the possibility of diversion of lower quality seafood into this sector, which might undermine the effectiveness of the law. This paper does not consider white table cloth restaurants where quality and safety of seafood may not be an issue.

To address the economic impact of the MCOOL law in the foodservice and retail sector, this paper develops a conceptual model that explores diversion of imported seafood to the non-labeled sector. The model is a variant of the model of vertical product 
differentiation by Mussa and Rosen (1978) and explicitly accounts for differences in consumer attitudes towards foreign and domestic seafood, which are facilitated by origin labeling. Consumers are postulated to differ in the utility they derive from the consumption of domestic and foreign seafood. We assume that consumers consider foreign fish to be of lower quality compared to domestic fish. This assumption that consumers perceive domestic fish to be of higher quality than imported fish is reinforced by a) recent safety incidents with imported products, b) media reports on fish farming practices in developing countries and the ineffective inspection of imports, and c) presentations in popular magazine and newspaper articles of the healthy seafood guide, which informs consumers to avoid most imported fish (www.edf.org/seafood). ${ }^{1}$ Wimberley et al. (2003) found that 80 percent of U.S. consumers believe that food produced or raised in the United States is fresher and safer than imported food.

MCOOL law is a retail labeling program, which brings us to the question of mandatory labeling in the foodservice sector. The absence of labeling (mandatory or voluntary) may result in an information problem between consumers and sellers. More specifically, in the foodservice market, consumers are not informed of the origin of seafood that sellers know about. ${ }^{2}$ This information deficit may lead consumers to make choices they would not have made with full information. We assume as in Lusk et al. (2006), that country of origin is often associated with product quality. Like nutritional

\footnotetext{
${ }^{1}$ However, it is not always the case that imported seafood is of lower perceived quality than domestic seafood. For example, Mexican shrimp is considered to have superior flavor and texture over domestic or other imported shrimp (Cavanaugh, 2003).

${ }^{2}$ It is reasonable to expect sellers (in this case foodservice operators) are aware of the origin of fish and shellfish. They are better informed about the ingredients used in prepared meals, proportions in which they are mixed, and the cooking methods used.
} 
attributes, quality is a credence attribute that implies consumers cannot learn about the characteristics of a product readily through inspection or even after consumption (Nelson 1970; Darby and Karni 1973). However, a credence attribute can be transformed into a search attribute. With COOL, quality becomes a search attribute because the label provides information about seafood products that may affect the consumers' perception and evaluation of its quality.

In markets where sellers are better informed about product quality (or origin in our case) than consumers, and when consumers may have perceptions of the risk and hazards of consuming products from certain countries, the key factor in determining whether markets for higher quality attributes operate effectively is the success of quality signaling (e.g., labeling, advertising, warranties) by sellers to consumers (Caswell and Mojduszka, 1996). Several theoretical and empirical studies on quality-signaling models explore how communication (voluntary and mandatory) between sellers and consumers takes place. ${ }^{3}$ For example, Akerlof's (1970) “lemons” model provides the classic argument for how asymmetric information may hinder markets. In this model, quality cannot be signaled. As a result a market may not exist or only the lowest-quality product may be sold.

On the other hand, voluntary communication addressed by Grossman's (1981) “unfolding model” predicts a market exists for varying levels of quality when quality signaling is totally effective, costless, and truthful, and consumers can costlessly verify

\footnotetext{
${ }^{3}$ A literature on informational unraveling suggests that voluntary and mandatory disclosure yield the same outcome, as long as the information is verifiable with zero cost, as first studied by Grossman (1981) and Milgrom (1981). Voluntary disclosure leads to only partial unraveling of information is shown by Jovanovic (1982), Farrell (1986), Fishman and Hagerty (2003), and Jin (2003). Jin (2003) and Mathios (2000) show empirical investigations of informational unraveling.
} 
quality after their purchases. Spence’s (1977) "signaling theory” argues that some sellers may voluntarily try to reduce asymmetric information by sending signals to consumers. Warranties are often considered a common type of signal sent by "high quality" firms to reduce the consumers' information gap on the quality of their products. Thus, voluntary labeling works well if enough consumers know the value of a product characteristic, if producers have a credible method of labeling their products, and if consumers are skeptical of firms that do not label their products.

In contrast, Fishman and Hagerty (2003) develop a model in which a subset of consumers does not either comprehend disclosure or understand the importance of the undisclosed attribute. Also, Mathios (2000) found that in the market for salad dressings there is less than perfect unraveling of information, meaning some of the firms with dressings in the middle range of the fat distribution chose not to disclose, and some of the worst chose to disclose.

These models indicate that mandatory labeling may have an impact on product choices. Mandatory disclosures in contrast to voluntary disclosures make it practicable for consumers to judge quality before purchasing a product by establishing a quality scale, requiring testing of quality, and mandating a reporting format. Caswell and Mojduszka (1996) state that the presence of imperfect information, transaction costs in acquiring and using information and externalities may make private markets for quality work inefficiently. Thus, quality signaling through mandatory product labeling and information disclosure requirements encourages market incentives with relatively limited government involvement. 
Information about food quality may have public good characteristics. Information is an economic good that markets do not always create and disseminate efficiently, as they would handle other kinds of goods and services. The government can step in to provide information that private markets may not provide when that information is needed by individuals to make better personal decisions. In this case, food quality (origin in our case) may be over- or undersupplied and government often intervenes in an attempt to correct or mitigate imperfections. Mandatory labeling of origin has been in practice in some states of the United States where products from other countries must be labeled according to their origin whereas domestic products are not labeled. For example, Alabama, Arkansas, Mississippi, and Louisiana have origin labeling requirements for certain seafood products. However voluntary state and regional labeling has also been implemented in the United States. Some products sold in grocery stores are identified with the area of production in the United States. Some examples are: Washington apples, Vermont maple syrup, Mississippi farm-raised catfish, Alaskan salmon, Georgia Vidalia onions, Idaho potatoes, and Jersey fresh produce. ${ }^{4}$

The fact that some retailers already label seafood as to its source indicates that market participants will provide country of origin information in response to market demand. This suggests there is no compelling market failure argument regarding MCOOL implementation. This stems from a lack of evidence of barriers to private provision of voluntary COOL should consumer demand support the increased costs of such labeling. To analyze the question of market failure warranting MCOOL law

\footnotetext{
${ }^{4}$ State and regional labeling programs, such as "Washington Apples," "Idaho potatoes," and "California Grown" do not meet the law requirement and so cannot be used in lieu of COOL (USDA-AMS, 2004). Here we consider such labeling programs as Voluntary COOL.
} 
implementation, we consider consumer and total welfare under alternate scenarios such as voluntary labeling, no labeling, and total labeling to compare with partial MCOOL.

While no one has specifically studied the economic impacts of partial coverage of the MCOOL law, others have noted that advantage may be taken of loopholes. For example, in their study of the consequences of COOL in the pork industry, Iqbal, Kim, and Rude (2006) write “(...) if U.S. retailers chose not to incur the extra costs of stocking Canadian pork, there are alternative outlets for Canadian pork including processed products and the HRI trade (p. 19)." ${ }^{5}$ Similarly, USDA-AMS (2004) states “(...) the majority of the sales of the covered commodity are through channels not affected by this rule, which provides substantial marketing opportunities for products without verifiable country of origin claims.” Another example is Tim Hammonds (2003), the president of the Food Marketing Institute (FMI), who says “(...) ranchers unable to document the history of their animals will find themselves unable to sell to supermarkets forcing their beef into the export or foodservice sectors, which are not covered under COOL regulation.”

Discussion on the implications of MCOOL implementation is not novel. Krissoff et al (2004) examined in detail the economic rationale behind the various claims about the effects of mandatory country-of-origin labeling on the beef, pork, and fruits and vegetables industries. The assumptions and findings are influenced heavily by the nature and structure of these markets. Other implications have been outlined in discussing the effects of MCOOL implementation by Peel (2008), Meyer (2008), and VanSickle (2008) for the beef, pork, and fruits and vegetables industries respectively. To date there is no

\footnotetext{
${ }^{5}$ HRI trade refers to Hotel, Restaurant, and Institutional trade.
} 
comprehensive report on the partial implementation of MCOOL law for the seafood industry. The seafood industry is very different from the meat industry as most seafood consumed in the United States is imported from developing countries while meat consumed in United States is mostly domestic.

This work is therefore a step towards analyzing the effect of partial MCOOL policy in the seafood industry taking into consideration the nature of the industry. The contributions of this paper are its distinct focus on the economic impacts of partial coverage of MCOOL in the seafood industry on consumers and sellers, and the question of market failure warranting MCOOL implementation in the United States. This paper also accounts for imperfect competition among retailers and the foodservice sectors, and models consumer heterogeneity characterized by different preferences for quality. A related work is USDA-AMS (2004), which is a detailed study of MCOOL in the seafood industry. Using a CGE model, the study determines costs incurred in the supply chain as a result of this regulation. It assumes that retailers are perfectly competitive and that COOL does not result in increased consumer demand for domestic products. Plastina and Giannakas (2007) account for imperfect competition among retailers for specialty crops, and consider consumer and producer heterogeneity in determining the welfare effects on supply chain participants when COOL is implemented. Their model assumes total implementation of COOL.

\section{The Model}

The model builds on Zago and Pick (2004) who analyze the welfare impact of labeling policies on agricultural commodities with credence attributes. Our analysis considers two scenarios, namely, the absence of MCOOL in the market and the presence 
of MCOOL law implementation. In the absence of MCOOL law implementation, we consider two cases. In the first case, there is no labeling and the origin of seafood cannot be distinguished by consumers. Consequently, quality based on origin cannot be ascertained (product appears undifferentiated to consumers), resulting in imperfect and asymmetric information. While consumers are unable to differentiate domestic fish from foreign, we assume that sellers in retail and foodservice sectors can differentiate them. The other case is voluntarily labeling of domestic seafood in the retail sector. We study this case to consider fish such as salmon, which was labeled prior to the implementation of the law. This case will also help us determine under which circumstances retailers would choose to voluntarily label.

In the presence of MCOOL law implementation, however, the sectors are segmented with quality differentiation generating a higher price for domestic than foreign fish. ${ }^{6}$ Retail and foodservice establishments that implement COOL can now exercise second-degree price discrimination, where consumers self-select themselves by choosing between two price-quality bundles. Thus, the sectors with MCOOL implementation are segmented into low- and high-quality markets. Two cases are considered in the presence of MCOOL law implementation for welfare implications: current partial MCOOL implementation (retail sector labeled) and total MCOOL implementation (both retail and foodservice sectors labeled).

The seafood supply chain is characterized by fish farmers (harvesters/producers), intermediaries (processors, importers, wholesalers and handlers) and retailers/foodservice

\footnotetext{
${ }^{6}$ Assuming that minimum average cost of production is greater for high quality than for low quality, it follows that market equilibrium prices $p_{H}$ and $p_{L}$ satisfy the condition $p_{H}>p_{L}$ (Antle, 2001).
} 
establishments. For simplicity we consider two levels: firms and establishments; where firms include fish farmers and intermediaries, and establishments are defined as retailers/foodservice establishments. Firms are further classified as foreign and domestic based on the origin of seafood supplied. In this model, domestic and foreign firms supplying seafood are considered to be perfectly competitive. Following previous literature (Sexton et al., 2003; Richards and Patterson, 2003), we assume retail and foodservice establishments exercise market power over consumers.

We consider a one-period game under vertical differentiation, with two qualities for a single good. The domestic country is the United States and the foreign country is the major exporter of seafood to the United States. We assume the quality, $k$, of seafood is exogenous. The quality of seafood products is defined here to depend on location and conditions of catch or aquaculture, processing, and handling throughout the supply chain (Caswell, 2006). In keeping with the assumption that the domestic seafood industry is regulated by the government with stricter policies, and the foreign seafood industry has to follow certain standards, but may not be subjected to stringent enforcement, the domestic firm produces high-quality seafood and the foreign firm produces products that are assumed to be of lower quality or are at least perceived as such. Thus, quality can be either low $\left(k_{L}\right)$ or high $\left(k_{H}\right)$. Domestic and foreign firms produce seafood with different production technologies and costs of production. Parameters $c_{L}$ and $c_{H}$ reflect production costs for the two qualities such that $c_{L}<c_{H}$. That is, foreign fish can be produced (and sold) at a lower price than domestic fish. 


\section{Supply side}

Following Zago and Pick (2004) and Bureau, Marette, and Schiavina (1998), we assume each firm $j$ (supplier of seafood to retail/foodservice), where $j=1$ to $n$, maximizes its profit $\pi_{i j}$, and produces a quantity $q_{i j} \in \mathfrak{R}_{+}$of the type $i=L, H$ where $i$ represents quality. The aggregate supply $q_{i}=Q_{i}\left(w_{i}\right)$ is the summation of individual supply $q_{i j}$ for each quality $i . w_{i}$ is the market price of selling seafood to the retail or foodservice sector. The overall surplus of the firms, $\Pi_{i}$, is the sum of individual profits $\pi_{i j}$. The analytical expression of surplus for firms of quality $i$ seafood is: ${ }^{7}$

$$
\pi_{i j}=q_{i j} w_{i}-0.5 c_{i}\left(q_{i j}\right)^{2}
$$

We consider a quadratic cost function, i.e., cost increases at an increasing rate and there is no decreasing marginal costs. This way, the law of diminishing marginal returns is followed. The expression for aggregate supply function is given as:

$$
Q_{i}\left(w_{i}\right)=w_{i} / c_{i}
$$

\section{Demand side}

To analyze consumer welfare, consider a conceptual model of heterogeneous consumers. The model is a variant of the classic model of vertical product differentiation by Mussa and Rosen (1978) and explicitly accounts for differences in consumer attitudes towards quality of fish. There is a continuum of consumers indexed by their preference $\theta$

\footnotetext{
${ }^{7}$ The first order conditions imply $\frac{\partial \pi_{i j}}{\partial q_{i j}}=0 \Rightarrow \sum_{j=1}^{n} \frac{\partial \pi_{i j}}{\partial q_{i j}}=0: w_{i}-c_{i} \sum_{j=1}^{n} q_{i j}=0 \Rightarrow w_{i}-c_{i} Q_{i}=0$.
} 
(or willingness to pay) for fish quality, which is uniformly distributed over $[0, \bar{\theta}]$ with density $1 / \bar{\theta}{ }^{8}$ We assume that each consumer buys at most one unit of the good with quality $k$. The associated utility is:

$$
U=\theta k-p
$$

where $p$ is the price of the good of quality $k$. Aggregate demand depends on consumers' beliefs about the quality, i.e., consumers' information about the origin of seafood available in the market. Without COOL, consumers believe they are consuming seafood of expected quality $\bar{k}$ while with COOL, consumers relate origin information of seafood to their perceived quality, denoted by $k_{H}$ and $k_{L}$. This assumption follows Lusk et al. (2006) who write “...consumers will make an assumption about the average quality of the product on the market. Because the market will contain products from a variety of origins, the expected quality of the product on the market might fall well below the perceived quality of the domestic product (p. 286).” We assume that with asymmetric information in the non-labeled market, consumers evaluate seafood quality using a simple average: $\bar{k}=\left(k_{H}+k_{L}\right) / 2$.

\section{Pre-MCOOL: No Labeling}

In the absence of MCOOL law implementation (no labeling), origin and production method cannot be determined by the consumers. That is, there is imperfect information in the market. Further, there is asymmetric information as sellers are aware of the origin and production of fish while consumers cannot identify them. In the extreme

\footnotetext{
${ }^{8}$ It should be noted that as the lower bound of the taste distribution is equal to zero, the market will not be entirely covered, i.e., some consumers prefer not to buy the good offered.
} 
case, if a consumer has no information about the quality of the product, sellers will resort to selling the lowest possible quality of a good.

We make the assumption that in the absence of labeling, the retail and foodservice sectors sell only foreign seafood because, in the context of this model, they do not have an incentive to sell domestic seafood. ${ }^{9}$ Figure 1 panel a shows schematically the seafood market in the absence of MCOOL law implementation.

The retail and foodservice sectors are considered two separate markets. We consider two separate markets because with the implementation of MCOOL the foodservice sector is "exempt" from labeling. In both markets, consumers are heterogeneous in their preference for quality and are postulated to differ in the utility or marginal willingness to pay that they derive from the quality of seafood. We assume that consumers have the same valuation for quality in the two markets. A unique price $\bar{p}$ develops in both sectors and consumers have an expected quality $\bar{k}$ as mentioned above. The conditional indirect utility function of a consumer with preference parameter $\theta$ in the retail and foodservice market is given by:

\footnotetext{
${ }^{9}$ The framework considered here implies that consumers do not know the actual quality of seafood supplied and would consume foreign seafood in the absence of labeling because there is also uncertainty about the extent to which it is potentially unsafe for their health. However, when information is available about the origin of seafood, some consumers are willing to pay more for domestic seafood.

In the absence of information regarding the origin of seafood, domestic and foreign fish are marketed together and the price received by establishments is the same regardless of which product is produced (pooling equilibrium; see Akerlof 1970). The absence of a premium for domestic seafood when they are not segregated, coupled with increased costs of producing domestic seafood, result in the profitability of the domestic fish being lower than that of foreign fish. In this case the supply of domestic seafood is not incentive compatible; market forces lead to failure of the market to satisfy expressed consumer demands. Hence, only foreign seafood is sold in the non-labeled sector.
} 
(4) $U= \begin{cases}\theta \bar{k}-\bar{p} & \text { if consumes a unit of seafood of expected quality } \bar{k} \text { at price } \bar{p} \\ 0 & \text { if consumes nothing }\end{cases}$

The indifferent consumer between consuming a unit of seafood and not consuming can be characterized as:

(5) $\quad \theta_{0}=\frac{\bar{p}}{\bar{k}}$

Consumers with valuation for quality greater than $\theta_{0}$ will buy seafood and consumers with valuation for quality lower than $\theta_{0}$ will not buy seafood. Thus, the demand for seafood in a market with no differentiation can be found by aggregating the quantity consumed by consumers with $\theta>\theta_{0}$. Normalizing $\bar{\theta}=1$, the demand at retail or foodservice with no labeling corresponds to:

$$
D_{0}(\bar{p})=1-\frac{\bar{p}}{\bar{k}}
$$

To determine the equilibrium quantity and price in the absence of MCOOL implementation, we solve the profit-maximization function for the retail and foodservice sectors. Then, derived demands at the retail and foodservice levels are equated with the supply of foreign firms. The two sectors are each characterized by $N$ identical retailers and $N$ identical foodservice establishments competing with each other and who have market power over consumers. The individual retailer/foodservice establishment $\mathrm{m}$ $(m=1, \ldots, N)$ maximizes profit given by:

$$
\max _{q_{0 m}} \prod_{m}^{N C}=\left[\bar{p}\left(Q_{0}\right)-w_{L}\right] q_{0 m}
$$


where $\bar{p}\left(Q_{0}\right)=\bar{k}\left(1-Q_{0}\right)$ is the inverse demand for non-labeled seafood in retail or foodservice. $w_{L}$ represents the price of foreign seafood paid by retailers and foodservice establishments to foreign firms. ${ }^{10}$ The superscript $N C$ refers to the scenario with no labeling. The first-order conditions of (7) imply:

$$
\frac{\partial \Pi_{m}^{N C}}{\partial q_{0 m}}=0 \Rightarrow \bar{k}\left(1-Q_{0}\left(1+\eta_{m}\right)\right)=w_{L}
$$

where $\eta_{m}=\frac{\partial Q_{0}}{\partial q_{0 m}} \frac{q_{0 m}}{Q_{0}}$ represent the conjectural variation elasticity of the retailer/foodservice establishment $m$. Because we assume identical retailers and foodservice establishments, each firm's conjectural variation elasticity is identical in equilibrium, i.e., $\eta_{1}=\eta_{2}=\ldots=\eta_{m}=\eta$. In this context, the firm's individual first-order condition corresponds to the aggregate first-order condition, i.e.,

$$
\bar{k}\left(1-Q_{0}(1+\eta)\right)=w_{L}
$$

Equation (9) represents the aggregate derived demand facing foreign firms from the retail or the foodservice sector.

When the parameter $\eta \in[0,1]$ is zero, it implies the establishments have no market power, while $\eta=1$ implies perfect collusion.

Equating derived demand (9) facing the foreign firms, aggregated over retail and foodservice establishments, with supply (2) indicates the following:

$$
\frac{2\left(\bar{k}-w_{L}\right)}{\bar{k} \lambda}=\frac{w_{L}}{c_{L}}
$$

\footnotetext{
${ }^{10}$ We assume the retail and foodservice sector incur the same costs of purchasing foreign seafood and other costs are assumed to be zero for simplicity.
} 
where $\lambda=(1+\eta)$. Solving for $w_{L}$ gives the equilibrium quantities and prices:

(11) $w_{L}^{*}=\frac{2 \bar{k} c_{L}}{\bar{k} \lambda+2 c_{L}}$

(12) $Q_{0}^{*}=\frac{\bar{k}}{\bar{k} \lambda+2 c_{L}}$

(13) $\bar{p}^{*}=\frac{\left(\bar{k} \eta+2 c_{L}\right) \bar{k}}{\bar{k} \lambda+2 c_{L}}$

The superscript notation * refers to equilibrium. Welfare measures with no labeling can be considered as a benchmark when evaluating the effects of MCOOL implementation.

Using (13), consumers' surplus with no labeling (indexed by $N C$ ) can be calculated by integrating consumer utility at equilibrium for consumers who consume a unit of seafood with willingness to pay for quality greater than $\theta_{0}$ in foodservice/retail:

$$
C S^{N C}=\int_{\theta_{0}}^{1}\left(\theta \bar{k}-\bar{p}^{*}\right) d \theta=\frac{\bar{k}^{3}}{2\left(\bar{k} \lambda+2 c_{L}\right)^{2}}
$$

Equation (14) is used to aggregate consumer surplus in the two sectors to get expected consumer welfare:

(15) $\quad C S^{N C}=\frac{\bar{k}^{3}}{\left(\bar{k} \lambda+2 c_{L}\right)^{2}}$

Equation (15) shows that consumer welfare depends positively on the expected quality of seafood and negatively on the costs of producing low-quality fish and the market power of establishments.

For the purpose of welfare analysis of MCOOL implementation, we also compute real consumer surplus. Real consumer surplus considers that while consumers believe 
seafood is of quality $\bar{k}$, it is in fact $k_{L}$. The aggregate real consumer surplus for the same set of consumers and prices in equilibrium as before is given as:

$$
C S_{\text {real }}^{N C}=\int_{\theta_{0}}^{1}\left(\theta k_{L}-\bar{p}^{*}\right) d \theta=\frac{\bar{k}\left(\bar{k} k_{L}-\Delta k\left(\bar{k} \eta+2 c_{L}\right)\right)}{\left(\bar{k} \lambda+2 c_{L}\right)^{2}}
$$

where $\Delta k=k_{H}-k_{L}$. Under real consumer surplus, both the price and the indifferent consumer between buying or not is determined according to the value of the quality actually consumed $k_{L}$.

Profit earned by retail and foodservice sectors can be calculated by substituting prices and quantities in equation (7) with equilibrium prices and quantities. The expression for total profit aggregated over retail and foodservice sectors is given as:

$$
\Pi^{N C}=\frac{2 \bar{k}^{3} \eta}{\left(\bar{k} \lambda+2 c_{L}\right)^{2}}
$$

Equation (17) shows that profit depends positively on the expected quality of seafood and market power parameter, and negatively on the costs of producing low-quality fish. Total welfare is the summation of real consumer surplus and profit which is:

$$
T W^{N C}=\frac{\bar{k}\left(\bar{k} k_{L}-\Delta k\left(\bar{k} \eta+2 c_{L}\right)\right)+2 \bar{k}^{3} \eta}{\left(\bar{k} \lambda+2 c_{L}\right)^{2}}
$$

\section{Pre-MCOOL: Voluntary COOL at Retail}

Prior to the implementation of MCOOL, some retailers may have voluntarily disclosed origin information for domestic seafood and may have chosen not to provide information about foreign seafood whose value to consumers may be less than its associated disclosure cost. Disclosing information about domestic seafood may be 
especially valuable when consumers have a strong willingness to pay for domestic seafood. The retailer can then segment the market and implement profitable second degree price discrimination. We examine this case as an alternative benchmark scenario.

In this case the retail sector will differentiate domestic seafood (identified by labels) from foreign seafood. In the retail sector domestic seafood is indexed by quality $k_{H}$ whereas non-labeled seafood is indexed by quality $\bar{k}$. In the absence of labels consumers cannot identify the origin of seafood and perceive it to be of average quality. Perceived quality $k_{H}$ is greater than average quality $\bar{k}$ and corresponding prices for seafood at retail are $p_{H}$ and $\bar{p}$ with $p_{H}>\bar{p}$.

Again let us consider two firms, domestic and foreign, selling to two sectors: retail and foodservice. We assume all domestic seafood is supplied to retail because it is labeled and foreign seafood is supplied to both the foodservice (non-labeled sector) and the retail sector, where it is not labeled. A schematic representation of this case is shown in Figure 1 panel b.

As in the previous model, there is a continuum of consumers with preference $\theta$ for quality. With voluntary labeling facilitating differentiation of domestic from foreign seafood in the retail sector, the indirect utility of a consumer is given by:

$U= \begin{cases}\theta k_{H}-p_{H} & \text { if consumes a unit of domestic seafood in retail sector } \\ \theta \bar{k}-\bar{p} & \text { if consumes a unit of seafood of expected quality in retail sector } \\ 0 & \text { if consumes nothing }\end{cases}$

Similarly, in the foodservice sector it is: 
$U= \begin{cases}\theta \bar{k}-\bar{p} & \text { if consumes a unit of seafood of expected quality in foodservice sector } \\ 0 & \text { if consumes nothing }\end{cases}$ where $\bar{k} \leq k_{H}$. There are two indifferent consumers in the retail sector: one is indifferent between consuming domestic seafood and non-labeled seafood $\left(\theta_{H}\right)$, and one between consuming non-labeled seafood and not consuming at all $\left(\theta_{0}\right)$. Similarly, in the foodservice sector, consumers are indifferent between consuming non-labeled seafood and not consuming at all $\left(\theta_{0}\right)$. Accordingly, the indifferent consumers (using 19 and 20) and the demand for each quality of seafood can be found by aggregating the quantity consumed of each type in the two sectors and are given at retail by:

$$
\begin{array}{ll}
\theta_{H}=\frac{p_{H}-\bar{p}}{k_{H}-\bar{k}} & D_{H}\left(p_{H}, \bar{p}\right)=1-\frac{p_{H}-\bar{p}}{k_{H}-\bar{k}} \\
\theta_{0}=\frac{\bar{p}}{\bar{k}} & D_{0}\left(p_{H}, \bar{p}\right)=\frac{p_{H}-\bar{p}}{k_{H}-\bar{k}}-\frac{\bar{p}}{\bar{k}}
\end{array}
$$

where $D_{H}$ and $D_{0}$ are demand for domestic and non-labeled seafood in the retail sector.

In foodservice, they are given by:

$$
\theta_{0}=\frac{\bar{p}}{\bar{k}} \quad D_{0}(\bar{p})=1-\frac{\bar{p}}{\bar{k}}
$$

where $D_{0}$ is demand for non-labeled seafood in the foodservice sector.

Voluntary labeling entails costs to retailers and domestic firms. Domestic fish producers and harvesters incur the cost of establishing and maintaining a recordkeeping system for origin and production information, and for product identification, labor, and training. Consequently retailers need to incur costs associated with labeling domestic 
seafood. The cost of labeling/recordkeeping borne by retailers is denoted as $b$ and operating costs (segregation and identity preservation costs) are denoted as $y$.

To determine equilibrium quantity and price, the profit-maximization function for the individual retailer and foodservice is solved first as each retailer $m$ maximizes its profit given by:

$$
\max _{q_{H m}, q_{0 m}} \Pi_{r m}^{V C}=\left[p_{H}\left(Q_{H}, Q_{0}\right)-w_{H}-b\right] q_{H m}+\left[\bar{p}\left(Q_{H}, Q_{0}\right)-w_{L}\right] q_{0 m}
$$

where $\quad p_{H}\left(Q_{H}, Q_{0}\right)=k_{H}-k_{H} Q_{H}-\bar{k} Q_{0} \quad$ and $\quad \bar{p}\left(Q_{H}, Q_{0}\right)=\bar{k}\left(1-Q_{H}-Q_{0}\right) . \quad$ The superscript $V C$ refers to a scenario with voluntary labeling at retail. The first-order conditions of (23) imply:

$$
\begin{aligned}
& k_{H}-k_{H} Q_{H} \lambda_{H}-\bar{k} Q_{0} \lambda_{H}=w_{H}+b \\
& \bar{k}\left(1-Q_{0} \lambda_{0}-Q_{H} \lambda_{0}\right)=w_{L}
\end{aligned}
$$

where $\lambda_{H}=\left(1+\eta_{H}\right)$ and $\eta_{H}=\frac{\partial Q_{i}}{\partial q_{H}} \frac{q_{H}}{Q_{i}}$. Similarly $\lambda_{0}=\left(1+\eta_{0}\right)$ and $\eta_{0}=\frac{\partial Q_{i}}{\partial q_{0}} \frac{q_{0}}{Q_{i}}$. Here $Q_{i}$ can be $Q_{H}$ or $Q_{0}$. Assume $\eta_{H}=\eta_{0}=\eta$, therefore $\lambda_{H}=\lambda_{0}=\lambda$. Equation (24) represents the derived demand facing domestic and foreign firms in the retail sector after solving simultaneously for $Q_{H}$ and $Q_{0}$. Each foodservice establishment $m$ maximizes its profit given by:

$$
\max _{q_{0 m}} \prod_{f m}^{V C}=\left[\bar{p}\left(Q_{0}\right)-w_{L}\right] q_{0 m}
$$

where $\bar{p}\left(Q_{0}\right)=\bar{k}\left(1-Q_{0}\right)$ is the inverse demand for seafood in the foodservice sector. The first-order conditions of (25) imply:

$$
\bar{k}\left(1-Q_{0} \lambda\right)=w_{L}
$$


where $\lambda=(1+\eta)$ and $\eta=\frac{\partial Q_{0}}{\partial q_{0}} \frac{q_{0}}{Q_{0}}$. Equation (26) represents the derived demand facing foreign firms in the foodservice sector.

With voluntary labeling, two markets emerge: one for high-quality and the other for low-quality seafood. Domestic firms supplying high-quality seafood incur an additional cost $y$ while the foreign firms' supply function for low-quality seafood remains unchanged. Following equations (1) and (2), supply in the two markets can be written as:

$$
\begin{aligned}
& Q_{H}=w_{H} /\left(c_{H}+y\right) \\
& Q_{0}=w_{L} / c_{L}
\end{aligned}
$$

Equating aggregate derived demand of the retail and foodservice sectors (24 and 26) with supply of domestic and foreign firms (27) indicates the following:

$$
\begin{aligned}
& \frac{\Delta k-2\left(w_{H}-w_{L}+b\right)}{\Delta k \lambda}=\frac{w_{H}}{c_{H}+y} \\
& \frac{\bar{k}-w_{L}}{\bar{k} \lambda}+\frac{2 \bar{k}\left(w_{H}+b\right)-2 k_{H} w_{L}}{\bar{k} \Delta k \lambda}=\frac{w_{L}}{c_{L}}
\end{aligned}
$$

Using (28), equilibrium quantities and prices in the two sectors, and prices of domestic and foreign firms can be derived. Consumers' surplus in the retail and foodservice sectors, identified by subscript $r$ for retail and $f$ for foodservice are given as:

$$
\begin{aligned}
& C S_{r}^{V C}=\int_{\theta_{0}}^{\theta_{H}}\left(\theta \bar{k}-\bar{p}^{*}\right) d \theta+\int_{\theta_{H}}^{1}\left(\theta k_{H}-p_{H}^{*}\right) d \theta \\
& C S_{f}^{V C}=\int_{\theta_{0}}^{1}\left(\theta \bar{k}-\bar{p}^{*}\right) d \theta
\end{aligned}
$$

The expected consumer surplus with voluntary labeling is obtained by aggregating consumer surplus in the retail and foodservice sector. Similar to our previous 
argument, real consumer surplus in retail and foodservice can be derived by substituting real quality supplied in the non-labeled market $k_{L}$ in place of $\bar{k}$.

Profit can be calculated by substituting prices and quantities in equation (23 and 25) with equilibrium prices and quantities. Total welfare is expressed as the summation of real consumer surplus and profit.

Expressions for equation (29), for profit, and for total welfare are messy and complicated for doing analysis through comparative statics, so analysis is done using numerical simulations. Numerical simulation details can be found in the analysis section.

\section{Partial MCOOL: MCOOL Implementation in Retail}

The current U.S. regulation requires MCOOL in the retail sector, so consumers can distinguish between the domestic and foreign seafood indexed by quality $k_{H}$ and $k_{L}$ respectively in the model. Domestic seafood is assumed to be perceived to be of higher quality than foreign seafood, i.e., $k_{H}>k_{L}$, and corresponding prices for seafood at retail are $p_{H}$ and $p_{L}$ with $p_{H}>p_{L}$. We assume domestic seafood (higher quality) is supplied to retail because it is identifiable through labels. Foreign seafood (lower quality) is supplied to both the non-labeled foodservice sector and the labeled retail sector, where it is labeled as such. Retailers can now convey product quality information to consumers via origin labels and a separating equilibrium may be attained that efficiently sorts consumers into markets for different qualities with corresponding prices. However, in the foodservice sector, in the absence of labeling, only foreign seafood is supplied (see

footnote 9). Figure 1 panel c shows how MCOOL facilitates quality differentiation at retail. 
The indirect utility of a consumer in the retail and foodservice sectors in this case is given as:

$$
U= \begin{cases}\theta k_{H}-p_{H} & \text { if consumes a unit of domestic seafood in labeled (retail) sector } \\ \theta k_{L}-p_{L} & \text { if consumes a unit of foreign seafood in labeled (retail) sector } \\ 0 & \text { if consumes nothing }\end{cases}
$$

Similarly,

$$
U= \begin{cases}\theta \bar{k}-\bar{p} & \text { if consumes a unit of foreign seafood in non - labeled sector } \\ 0 & \text { if consumes nothing }\end{cases}
$$

where $k_{L} \leq \bar{k} \leq k_{H}$. Using (30) the indifferent consumers and the demand for each quality $(H, L)$ of seafood in retail are given by:

$$
\begin{array}{ll}
\theta_{H L}=\frac{p_{H}-p_{L}}{k_{H}-k_{L}} & D_{H}\left(p_{H}, p_{L}\right)=1-\frac{p_{H}-p_{L}}{k_{H}-k_{L}} \\
\theta_{L 0}=\frac{p_{L}}{k_{L}} & D_{L}\left(p_{H}, p_{L}\right)=\frac{p_{H}-p_{L}}{k_{H}-k_{L}}-\frac{p_{L}}{k_{L}}
\end{array}
$$

Using (31), the indifferent consumer and demand for non-labeled seafood are given by the following equations in the foodservice sector:

$$
\theta_{0}=\frac{\bar{p}}{\bar{k}} \quad D_{0}(\bar{p})=1-\frac{\bar{p}}{\bar{k}}
$$

As mentioned earlier there are costs associated with MCOOL implementation. MCOOL requires systems to be implemented to ensure that origin and production information is transferred from producers to the next buyers of their products, and that the information is maintained for the required amount of time. With MCOOL implementation in retail, domestic firms bear operating costs (segregation and identity preservation costs) $y$ whereas foreign firms do not. Exporters are assumed to not bear 
operating costs with MCOOL because they inform the country of origin with labels to the "ultimate purchaser" anyway, irrespective of MCOOL implementation. Ultimate purchaser has been defined as the last U.S. person who will receive the product in the form in which it was imported. Similar to the voluntary labeling scenario, retailers incur costs of labeling $b$. However, this cost applies to all seafood sold in retail, which includes domestic and foreign seafood.

Each retailer $m$ maximizes its profit given by:

$$
\max _{q_{H m}, q_{L m}} \prod_{r}^{P C}=\left[p_{H}\left(Q_{H}, Q_{L}\right)-w_{H}-b\right] q_{H m}+\left[p_{L}\left(Q_{H}, Q_{L}\right)-w_{L}-b\right] q_{L m}
$$

where $p_{H}\left(Q_{H}, Q_{L}\right)=k_{H}-k_{H} Q_{H}-k_{L} Q_{L}$ and $p_{L}\left(Q_{H}, Q_{L}\right)=k_{L}\left(1-Q_{H}-Q_{L}\right)$ are the inverse demand for domestic and foreign seafood at retail. The first-order conditions of (34) imply:

$$
\begin{aligned}
& k_{H}-k_{H} Q_{H} \lambda-k_{L} Q_{L} \lambda=w_{H}+b \\
& k_{L}\left(1-Q_{L} \lambda-Q_{H} \lambda\right)=w_{L}+b
\end{aligned}
$$

Equation (35) represents the derived demand facing domestic and foreign firms in the retail sector after solving simultaneously for $Q_{H}$ and $Q_{L}$.

Each foodservice establishment $m$ maximizes its profit given by:

$$
\max _{q_{0 m}} \prod_{f}^{P C}=\left[\bar{p}\left(Q_{0}\right)-w_{L}\right] q_{0 m}
$$

where $\bar{p}\left(Q_{0}\right)=\bar{k}\left(1-Q_{0}\right)$ is the inverse demand for seafood in the foodservice sector. The superscript $P C$ refers to a scenario with partial MCOOL implementation. The firstorder conditions of (36) imply:

$$
\bar{k}\left(1-Q_{0} \lambda\right)=w_{L}
$$


The above equation represents the derived demand facing foreign firms in the foodservice sector.

Supply in the high- and low-quality markets can be written as:

$$
\begin{aligned}
& Q_{H}\left(w_{H}\right)=w_{H} /\left(c_{H}+y\right) \\
& Q_{L}\left(w_{L}\right)=w_{L} / c_{L}
\end{aligned}
$$

Equating aggregate derived demand of the retail and foodservice sectors (35 and 37) with supply of domestic and foreign firms (38) indicates the following:

$$
\begin{aligned}
& \frac{\Delta k-\left(w_{H}+w_{L}\right)}{\Delta k \lambda}=\frac{w_{H}}{c_{H}+y} \\
& \frac{\bar{k}-w_{L}}{\bar{k} \lambda}+\frac{k_{L}\left(w_{H}+b\right)-k_{H}\left(w_{L}+b\right)}{k_{L} \Delta k \lambda}=\frac{w_{L}}{c_{L}}
\end{aligned}
$$

Consumers' surplus in the retail and foodservice sectors for this case are given as:

$$
\begin{aligned}
& C S_{r}^{P C}=\int_{\theta_{L 0}}^{\theta_{H L}}\left(\theta k_{L}-p_{L}^{*}\right) d \theta+\int_{\theta_{H L}}^{1}\left(\theta k_{H}-p_{H}^{*}\right) d \theta \\
& C S_{f}^{P C}=\int_{\theta_{0}}^{1}\left(\theta \bar{k}-\bar{p}^{*}\right) d \theta
\end{aligned}
$$

The expected consumer welfare after implementing MCOOL is obtained by aggregating consumer surplus in the retail and foodservice sector. The expressions for real consumer surplus, profit, and total welfare are derived as before. The expressions are not reported here but analyzed using numerical simulations in the analysis section.

\section{Total MCOOL: MCOOL Implementation in Retail and Foodservice}

Finally, we consider the case where MCOOL is implemented in both the retail and foodservice sectors. There is no informational asymmetry, consumers are able to determine the origin of seafood and make informed choices in both sectors. An important 
outcome of uniform regulation in both sectors is that there is no scope for diversion. Figure 1 panel $\mathrm{d}$ shows the case of a totally differentiated market. Here, labeling cost $b$ is applicable to both the foodservice and retail establishments. As before, cost $y$ is borne only by the domestic firms. The profit-maximization equation for the individual retailer/foodservice establishment $m$ becomes:

$$
\max _{q_{H m}, q_{L m}} \prod_{m}^{T C}=\left[p_{H}\left(Q_{H}, Q_{L}\right)-w_{H}-b\right] q_{H m}+\left[p_{L}\left(Q_{H}, Q_{L}\right)-w_{L}-b\right] q_{L m}
$$

where $p_{H}\left(Q_{H}, Q_{L}\right)=k_{H}-k_{H} Q_{H}-k_{L} Q_{L}$ and $p_{L}\left(Q_{H}, Q_{L}\right)=k_{L}\left(1-Q_{H}-Q_{L}\right)$ are the inverse demand for domestic and foreign seafood in retail or foodservice. The superscript $T C$ refers to a scenario with total MCOOL implementation. All other variables are as previously defined. The first order conditions of (41) imply:

$$
\begin{aligned}
& k_{H}-k_{H} Q_{H} \lambda-k_{L} Q_{L} \lambda=w_{H}+b \\
& k_{L}\left(1-Q_{L} \lambda-Q_{H} \lambda\right)=w_{L}+b
\end{aligned}
$$

The above equations can be solved for $Q_{H}$ and $Q_{L}$ to get the derived demand facing domestic and foreign firms in the retail and foodservice sectors. Equating aggregate derived demand of the retail and foodservice sectors (42) with supply of the domestic and foreign firms (38) indicates the following:

$$
\begin{aligned}
& \frac{2\left(\Delta k-\left(w_{H}+w_{L}\right)\right)}{\Delta k \lambda}=\frac{w_{H}}{c_{H}+y} \\
& \frac{2\left(k_{L} w_{H}-k_{H} w_{L}\right)}{k_{L} \Delta k \lambda}=\frac{w_{L}}{c_{L}}
\end{aligned}
$$

Consumer surplus at the retail or foodservice sector when both sectors are labeled is given by:

$$
C S^{T C}=\int_{\theta_{L 0}}^{\theta_{H L}}\left(\theta k_{L}-p_{L}^{*}\right) d \theta+\int_{\theta_{H L}}^{1}\left(\theta k_{H}-p_{H}^{*}\right) d \theta
$$


Expected consumer surplus is the same as real consumer surplus in a totally differentiated market as there is no mismatch between quality of seafood supplied and consumed.

\section{Analysis}

In this section, we examine the extent to which diversion occurs as a result of partial MCOOL implementation and the associated welfare effects. Diversion can be related to the concept of 'leakage' in the emissions leakage literature. Leakage refers to increases in production and associated emissions among unregulated producers that occur as a direct consequence of incomplete environmental regulation (CCAP, 2005; and RGGI, 2007). Fowlie (2009) states that when there is incomplete regulation, i.e., when pollution regulation is applied to only a subset of firms in a polluting industry, substantial leakage may occur since production at regulated firms can be substituted for unregulated production. Similarly, the partial implementation of MCOOL may lead to diversion or leakage of lower quality imports to the non-labeled sector. We define diversion as a percentage of the relative share of foreign seafood increase in the foodservice sector with partial implementation of MCOOL.

In our analysis, we consider the pre-MCOOL case (no labeling and voluntary labeling) as the benchmark to determine the effect of MCOOL (partial and total implementation) on welfare. Our welfare analysis focuses on consumer surplus (expected and real), profit, and total welfare (consumer surplus and profit).

Using Mathematica 6.0, we first calibrate the model to have positive prices and quantities in equilibrium. To calibrate the model, we normalize $c_{L}$ and $k_{L}=1$, fix $\eta=$ 
0.5 , set costs associated with labeling $b=0.07$ and $y=0.0025$, and then determine values for $c_{H}$ and $k_{H}$ in the feasible region (positive prices and quantities in equilibrium). In order to analyze the effect of change in quality on welfare and diversion within the feasible region, we fix $c_{H}$ at 4 and vary $k_{H}$ from $110 \%$ to $210 \%$ of $k_{L}$. We allow $k_{H}$ to have differences in quality from $10 \%$ to $100 \%$. Finally, we vary labeling costs $b$ from 0.05 to 0.15 for $k_{H}=1.1$ and 2 to analyze the incentive for retailers to voluntarily label domestic seafood as opposed to not label at all, by comparing profits across four scenarios - No Labeling, Voluntary COOL, Partial MCOOL, and Total MCOOL. All other parameters are set at the values mentioned above.

Table 1 summarizes welfare magnitudes for fixed parameter values for the four scenarios considered. The "high quality" parameter $k_{H}$ is set at 1.5 , and market power parameter $\eta$ is set at $0.5, b$ is set at 0.07 , all other parameters are set at values mentioned earlier.

The first two rows of Table 1 show the comparative magnitude of consumer surplus (expected and real) across four scenarios, namely, no labeling, voluntary COOL, partial MCOOL, and total MCOOL. For fixed parameter values, expected consumer surplus is greatest with partial MCOOL and real consumer surplus is greatest with total MCOOL. Expected consumer welfare in the partial MCOOL case does not take into account the real quality $k_{L}$ of foreign fish supplied to consumers in the non-labeled sector. Rather it is based on consumers' belief of quality $\bar{k}$, where $\bar{k}>k_{L}$. Thus, while consumers expect to be getting quality $\bar{k}$, they are in fact consuming seafood of perceived lower quality. Because consumer utility is dependent on the quality of the 
product consumed, consumer surplus is necessarily higher when consumers believe they are getting $\bar{k}$ rather than $k_{L}$. Considering that consumers are truly consuming quality $k_{L}$, real consumer surplus is greatest with total MCOOL. When both sectors are labeled, expected quality is equal to real quality, and consumers are aware of the quality of fish they consume and can make informed choices.

Real consumer surplus is greater under voluntary COOL than partial MCOOL because the quantity of perceived expected-quality fish consumed in retail, in the voluntary COOL scenario, is greater than the quantity of perceived low-quality fish consumed in retail under partial MCOOL. Equilibrium quantity comparisons for fixed parameter values under the two scenarios can be seen in Table 2 .

Profit is greatest under voluntary labeling followed by partial MCOOL, No labeling, and total MCOOL as shown in Table 1. A non-labeled market can lead sellers to take advantage of consumer misinformation. The absence of labels allows sellers to masquerade sales of low-quality fish as higher quality. As a result, consumers pay a higher price for low-quality seafood, which increases profit for establishments selling low-quality fish in the non-labeled market. Under voluntary labeling, retailers label domestic fish but not foreign fish. However, under partial MCOOL, retailers must label all fish. Thus, under voluntary COOL retailers take advantage of consumers' willingnessto-pay for domestic fish and their ignorance of quality of the foreign fish. This is reflected in equilibrium with the higher price-quality ratio for low-quality fish sold in both the retail and foodservice sectors under voluntary labeling compared to partial MCOOL. This leads to greater profit under voluntary COOL scenario. 
Table 1 shows that total welfare is greatest under voluntary COOL, followed by partial MCOOL, total MCOOL, and No labeling. The ranking follows that of profit, meaning that the profit component in total welfare dominates the effect of real consumer surplus.

\section{a. Diversion and the effect of quality on diversion}

We examine the effect of partial MCOOL on the quantity of low-quality fish diverted to the non-labeled market. We focus on the foodservice sector for our calculations of diversion because it is exempt under current MCOOL law. Before MCOOL implementation, neither retail nor foodservice sectors were required to be labeled. As a result there is no potential for diversion. However, with MCOOL implemented in the retail sector, low-quality fish may be diverted to the non-labeled sector. One way to measure diversion to the non-labeled market is to compare the quantity of low-quality fish sold to the foodservice sector (non-labeled) prior to partial MCOOL implementation, i.e., $Q_{0}^{* N C}$, with the quantity sold under partial MCOOL, i.e., $Q_{0}^{* P C}$. Substituting parameter values, the quantity sold to the foodservice sector before partial MCOOL is smaller than under implementation of the law. This would indicate diversion of low-quality fish to the non-labeled market. However, this measure may be misleading because it is possible that the total quantity of fish sold in the U.S. market (high- and low-quality) increases with the implementation of partial MCOOL. Thus, a relative measure of diversion is more accurate.

Diversion is measured by comparing the relative quantity of low-quality fish sold in the foodservice sector under partial implementation of MCOOL to the relative quantity 
sold in the absence of its implementation. The formula used to calculate diversion is given as:

$$
\text { diversion } \%=\frac{\frac{Q_{0}^{* P C}}{Q_{0}^{* P C}+Q_{H}^{* P C}+Q_{L}^{* P C}}-\frac{Q_{0}^{* N C}}{Q_{0}^{* N C}+Q_{0}^{* N C}}}{\frac{Q_{0}^{* N C}}{Q_{0}^{* N C}+Q_{0}^{* N C}}} * 100=\frac{\frac{Q_{0}^{* P C}}{Q_{0}^{* P C}+Q_{H}^{* P C}+Q_{L}^{* P C}}-\frac{1}{2}}{\frac{1}{2}} * 100
$$

Diversion is expressed as a percentage of relative share of low-quality fish sold in foodservice post and pre-MCOOL implementation. A diagrammatic representation is shown in Figure 2.

We find that at fixed parameter values, there is evidence of diversion as shown in Figure 3. At the initial parameter value of $k_{H}=1.1$, the diversion percentage has a value of 7.5 percent. This means that the share of low-quality fish in the foodservice sector with partial MCOOL is relatively larger than the share pre-MCOOL. Under partial MCOOL the price-quality ratio of seafood in the foodservice sector is lower than with preMCOOL. . Therefore, non-labeled fish from the food service sector under MCOOL is more attractive to consumers. This can be explained as follows. The pre-MCOOL market is characterized by the supply of low-quality foreign fish only, which consumers perceive to be of expected average quality $\bar{k}$. With partial MCOOL, high-quality domestic fish is also supplied to the labeled sector whereas the non-labeled sector behaves similarly to the pre-MCOOL market. Price competition in the partial MCOOL case between domestic and foreign seafood results in a lower price for expected quality fish in the non-labeled sector than in the pre-MCOOL case. Thus, the quantity of low-quality fish sold in the non-labeled sector after partial MCOOL implementation is greater than pre-MCOOL. 
Refer to Table 2 to compare equilibrium price and quantity across pre- and post-MCOOL scenarios.

Figure 3 shows that the greater the quality differences between domestic and foreign fish, the greater will be the diversion to the non-labeled market. The same intuition as above applies, i.e., this is explained by the larger difference in the pricequality ratio.

\section{b. Effect of increasing quality differences between domestic and foreign seafood on consumer surplus}

Expected consumer surplus increases in all four scenarios with increasing quality differences between domestic and foreign fish (Figure 4). In contrast, real consumer surplus increases for total MCOOL, but decreases for partial MCOOL, voluntary labeling, and No labeling (Figure 5). Real consumer surplus decreases for the No labeling case as consumers in reality are being supplied with low-quality fish despite their belief they are consuming fish of expected quality. As $k_{H}$ increases, expected quality $(\bar{k})$ increases, which increases the price and reduces the quantity of (foreign) fish consumed. However, the real quality $k_{L}$ does not change with an increase in the quality difference between domestic and foreign seafood. Thus, real consumer surplus decreases under No labeling as price-quality ratio increases with no change in real quality, which reduces the quantity consumed.

Increasing quality differences between domestic and foreign seafood results in real consumer surplus decreasing under voluntary COOL and partial MCOOL. This is because voluntary COOL and partial MCOOL scenarios are characterized by labeled and non-labeled sectors. The non-labeled sector under these scenarios behaves similarly to the 
No labeling scenario. That is, increase in $k_{H}$ does not change the real quality $k_{L}$ supplied. Thus, the price-quality ratio under voluntary COOL and partial MCOOL increases in the non-labeled sector with increasing quality differences. Under total MCOOL implementation, high- and low-quality labeled seafood are sold in both the sectors. With increasing quality differences, the price-quality ratio of high-quality seafood sold in retail is lower than the price-quality ratio of high-quality seafood sold under voluntary COOL and partial MCOOL scenarios. Similarly, the price-quality ratio of low-quality seafood sold in retail and foodservice sectors is lower than the ratio of low-quality seafood sold under voluntary COOL and partial MCOOL scenarios. This smaller price-quality ratio indicates that real consumer surplus becomes greater under total MCOOL compared with the other two scenarios.

Figure 5 shows that at low differences in quality between domestic and foreign fish, real consumer surplus under partial MCOOL is greater than total MCOOL, and voluntary COOL gives the highest real consumer surplus. This quickly reverses as the difference in quality between domestic and foreign fish increases. This is because when the quality difference becomes larger and consumer value quality, labeling allows consumers to sort qualities and benefit from it.

\section{c. Effect of increasing quality differences between domestic and foreign seafood on profit and total welfare}

The effect of increasing the quality difference on profit is shown in Figure 6. As $k_{H}$ increases, profit increases. Profit increases the most for scenarios characterized by non-labeled markets, as the perceived expected quality of fish increases but in reality low-quality fish is supplied. 
We analyze the effect of varying labeling costs on profit of firms across scenarios by considering two cases - low difference in quality $\left(k_{H}=1.1\right.$ and $\left.k_{L}=1\right)$ and high difference in quality ( $k_{H}=2$ and $\left.k_{L}=1\right)$. These cases are shown in Figure 7a and Figure 7b. Across both cases it can be seen that as cost increases, profit of firms decreases. Increase in labeling costs does not alter the ranking price-quality ratio for low-quality seafood across scenarios, i.e., price-quality ratio is higher for voluntary COOL compared to other scenarios. Thus, profit under voluntary labeling remains the highest. At low difference in quality (Figure 7a) and low labeling costs, profits are higher under total MCOOL but reverses as labeling costs increase. No labeling becomes preferable to total MCOOL with increasing $b$ because firms under No labeling scenario bear no costs whereas firms under total MCOOL bear costs of labeling both in the retail and foodservice sectors. Compared with a No labeling scenario, retail sector will voluntarily label domestic seafood because identification of origin leads domestic firms supply to a labeled market, consumers are willing to pay for quality, and the benefits of labeling outweigh the costs, in turn retailers make higher profits.

Total welfare has two components - real consumer surplus and profit. Figure 8 shows that increasing differences in quality between domestic and foreign fish $\left(k_{H}\right)$ increases total welfare for voluntary labeling, partial MCOOL, and total MCOOL but decreases total welfare for the No labeling scenario. The increase in total welfare is explained by the increase in profit with increasing quality differences, as profit overweighs real consumer surplus in magnitude. In contrast, the decrease in total welfare is explained by the decrease in real consumer surplus that overweighs profit in magnitude under No labeling scenario. 


\section{Conclusion}

The seafood market in the United States is characterized increasingly by imported fish and shellfish from developing countries. With the implementation of MCOOL in April 2005 in the seafood market, and the exemption of the foodservice sector from mandatory labeling, there is a potential for diversion of lower quality imports to the nonlabeled sector. In other words, while labeling satisfies the market demand for information provision in one market, exemptions in the other market create incentives for the diversion of imports, which are assumed to be lower in quality than domestic seafood, to the non-labeled sector. The diversion of lower quality seafood to the non-labeled market segment has consequences for the welfare impact of the implementation of partial MCOOL.

This paper develops a conceptual model of heterogeneous consumers that examines the consequences of partial MCOOL implementation on welfare and diversion. Numerical simulation results show that diversion is possible in the partial MCOOL scenario and the higher the perceived quality of domestic fish, the greater the diversion of low-quality imports to the non-labeled market. Real consumer surplus is greatest under total MCOOL implementation when quality differences between domestic and foreign fish are perceived to be great. However at low differences in quality, voluntary COOL is preferred to total MCOOL as real consumer surplus is greater under voluntary COOL. Profit is also greatest under voluntary COOL with both increasing quality differences and labeling costs.

Our work has several policy implications. If the goal of MCOOL policy is to provide consumers with information through retail labeling, and if consumers value 
quality (as previous studies have shown), then the likely unintended consequences of diverting food products into the non-labeled market as a result of partial COOL implementation need to be considered. This problem is especially important for fish and seafood as these products are consumed in large part in the foodservice sector-a nonlabeled market. Real consumer welfare and total welfare are greater under voluntary labeling than under the current partial implementation in retail only suggesting that there is no evident market failure argument that warrants the imposition of partial MCOOL law. Based on the goal of the law to provide consumers with information through retail labeling, and the extent to which consumers perceive the difference in quality, this law seems to be unnecessary. Some of our results are contingent on the fact that consumers value and consider domestic seafood to be of significantly higher quality than foreign seafood. Literature shows there are a number of studies on consumers' willingness to pay for origin of food products. Our results support more work on studying consumers' willingness to pay for domestic seafood. Thus, our study shows that voluntary labeling can mitigate asymmetric information problems arising from the credence nature of the origin of seafood products, and enhance consumer welfare.

The current state of the food industry, with numerous recent safety scares and publicity about safe seafood choices, has contributed to the perception that foreign fish is of lower quality than domestic fish. The nature of the industry characterized by a majority of imported seafood consumed away from home poses a real question about the effectiveness of retail-MCOOL. Though some labeling is perhaps better than none at all, partial labeling can lead to undermining the effectiveness of the regulation. 


\section{References}

Akerlof, G. A. 1970. “The market for 'lemons': Quantitative uncertainty and the market mechanism”. Quarterly Journal of Economics Vol. 89, pages 488-500.

Allshouse, J., J. Buzby, D. Harvey, and D. Zorn. 2004. "Seafood Safety and Trade”, Issues in Diet, Safety, and Health. Agriculture Information Bulletin, no.789-7, USDA, Economic Research Service, February.

Antle, J. M. 2001. "Economic analysis of food safety”, Handbook of Agricultural Economics, Chapter 19, Vol. 1. Edited by B. Gardner and G. Rausser.

Barboza, D. 2007. “In China, farming fish in toxic waters”. http://www.nytimes.com/2007/12/15/world/asia/15fish.html?ex=1198904400\&en =65bd935ad376f001\&ei=5070\&emc=eta1, (accessed on Dec, 2007)

Bureau, J. C., Marette, S., and A. Schiavina. 1998. "Non-tariff Trade Barriers and Consumers' Information: The Case of the E.U.-U.S. Trade Dispute over Beef”. European Review of Agricultural Economics. Vol. 25, pages 437-462.

Caswell, J. A., and E.M. Mojduszka. 1996. "Using informational labeling to influence the market for quality in food products”, American Journal of Agricultural Economics. Vol. 78, pages 1248-1253.

Caswell, J. A. 2006. "Quality Assurance, Information Tracking, and Consumer Labeling”. Marine Pollution Bulletin. Vol. 53, Issues 10-12, pages 650-656.

Cavanaugh, B. B. 2003. "Mexican shrimp make a big splash on seafood menus". Nation's Restaurant News. New York: Sept 22. Vol. 37, Iss. 38, p. 83, 152+

Center for Clean Air Policy. 2005. "Design of a Cap on Emissions from California Power Demand,” Technical Report, CCAP

Darby, M. R., and E. Karni. 1973. "Free Competition and the Optimal Amount of Fraud”. Journal of Law Economics, Vol.16, pages 67-88.

Farrell, J. 1986. "Voluntary Disclosure: Robustness of the Unraveling Results and Comments on Its Importance,” in R. Greison (ed.) Antitrust and Regulation, (Lexington Books).

Fishman, M. J. and K. M. Hagerty. 2003. "Mandatory vs. Voluntary Disclosure in Markets with Informed and Uninformed Customers," Journal of Law, Economics, and Organization, Vol. 19, No.1, pages 45-63. April. 
Fowlie, M. (2009). “Incomplete Environmental Regulation, Imperfect Competition, and Emissions Leakage”. (forthcoming American Economic Journal: Economic Policy).

Grossman, S. 1981. "Informational role of warranty and private disclosure of about product quality.” Journal of Law and Economics, Vol. 24, No. 3, pages 461-483, December.

Hale Group. 2005. “Restaurants are the key source of fish/seafood”. Alaska Seafood Marketing Institute. Foodservice E-newsletter, July. http://www.alaskaseafood.org/foodservice/news/july_news/industry.htm

Hammonds, T. 2003. "Retailer Expectations for Country-of-Origin Labeling”. Paper presented at AAEA Food \& Agricultural Marketing Policy Section Conference Emerging Roles for Food Labels: Inform, Protect, Persuade. Washington, D.C., March 20-21.

Iqbal, J., R. Kim, and J. Rude. 2006. “This Little Piggy Went to Market with a Passport: The Impacts of U.S. Country of Origin Labeling on the Canadian Pork Sector”. Canadian Journal of Agricultural Economics, Vol. 54, Issue 3, pages 401-420.

Jin, G. Z., and P. Leslie. 2003. “The Effects of Information on Product Quality: Evidence from Restaurant Hygiene Grade Cards.” Quarterly Journal of Economics, Vol. 118, No. 2, pages 409-51, May.

Jovanovic, B. 1982. “Truthful Disclosure of Information,” Bell Journal of Economics, Vol. 13, pages 36-44.

Keithly, W. R. 1985. "Social economic Determinants of At-Home Seafood Consumption: A Limited Dependent Variable Analysis of Existing and Latent Consumers”. Unpublished Ph.D. dissertation, University of Florida, Gainesville.

Krissoff, B., F. Kuchler, K. Nelson, J. Perry, and A. Somwaru. 2004. “Country-of-Origin Labeling: Theory and Observation,” Outlook Report No. (WRS04-02), January.

Los Angeles Times (2007). “At-risk Chinese seafood slipping through U.S. net”. Los Angeles California, pp.C.2, Business Part C, Business Desk. August 8.

Lusk, J. L., Brown, J., Mark, T., Proseku, I., Thompson, R., Welsh, J. 2006. “Consumer Behavior, Public Policy, and Country-of-Origin Labeling”. Review of Agricultural Economics, Vol. 28, No. 2, pages 284-292.

Mathios, A. D. 2000. “The Impact of Mandatory Disclosure Laws on Product Choices: An Analysis of the Salad Dressing Market.” Journal of Law and Economics, Vol. 43, No. 2, October. 
Meyer, S. R. 2008. "Implementation of Mandatory Country of Origin Labeling (MCOOL) in the Pork Industry,” Choices, 23(4).

Milgrom, P. 1981. "Good News and Bad News: Representation Theorems and Applications,” Bell Journal of Economics, Vol. 12, pages 380-91.

Mussa, M. and S. Rosen. 1978. "Monopoly and Product Quality”. Journal of Economic Theory, Vol. 18, Issue 2, pages 301-317.

National Marine Fisheries Service. (NMFS) 2007. "Fisheries of the United States-2005”. http://www.st.nmfs.gov/st1/fus/fus05/index.html (accessed Feb, 2007).

Nelson, P. 1970. "Information and consumer behavior". Journal of Political Economy, Vol. 78, pages 311-329.

Peel, D. S. 2008. "Implementation of Country of Origin Labeling (COOL) in the Beef Industry," Choices, 23(4).

Plastina, A., and K. Giannakas. 2007. "Market and Welfare Effects of Mandatory Country-of-Origin Labeling in the U.S. specialty crops sector”. Paper presented at the American Economics Association Annual Meeting, Portland, OR, July 29August 1.

Regional Greenhouse Gas Initiative Staff Working Group. 2007. “Potential emissions leakage and regional greenhouse gas initiative: Evaluating market dynamics, monitoring options, and possible mitigation options,” Technical Report.

Richards, T., and P. Patterson, 2003. "Competition in Fresh Produce Markets: An Empirical Analysis of Channel Performance”, Contractor and Cooperator Report 1, Economic Research Service, U.S. Department of Agriculture, September.

Sexton, R., Zhang, M., and J. Chalfant, 2003. "Grocery Retailer Behavior in the Procurement and Sale of Perishable Fresh Produce Commodities”. Contractors and Cooperators Report 2, Economic Research Service, U.S. Department of Agriculture, September.

Spence, M. 1977. "Consumer misperception, product failure and product liability.” Review of Economic Studies, Vol. 44, No. 3, pages 561-572, October.

Stewart, H., N. Blisard, S. Bhuyan, and R. M. Nayga, Jr. 2004. "The demand for food away from home Full-service or Fast food?” USDA Agricultural Economic Report no. 829. January.

The Catfish Institute (2007). www.catfishinstitute.com 
U.S. Department of Agriculture, Agricultural Marketing Service (USDA-AMS), 2004. "Mandatory Country of Origin Labeling of Fish and Shellfish; Interim Rule", Federal Register. Vol. 69(192), October 5.

VanSickle, J. 2008. “Country of Origin Labeling for Fruits and Vegetables,” Choices, 23(4).

Verlegh, P. W. J. and J. E. M. Steenkamp. 1999. “A review and meta-analysis of country of origin research”. Journal of Economics Psychology. Vol. 20, pages 521-46

Wimberley, R. C., B. J. Vander Mey, B.L. Wells, G.D. Ejimakor, C. Bailey, L.L.Burmeister, C.K. Harris, M.A. Lee, E.L. McLean, J.J. Molnar, G.W. Ohlendorf, T.J. Tomazic and G. Wheelock. 2003. "Food from our changing world: The globalization of food and how Americans feel about it”. Available at: http://sasw.chass.ncsu.edu/global-food.

Zago, A. M., and D. Pick. 2004. "Labeling Policies in Food Markets: Private Incentives, Public Intervention, and Welfare Effects”, Journal of Agricultural and Resource Economics, Vol. 29 Issue 1, pages 150-165. 
Table 1: Welfare magnitude comparisons for fixed parameter values.

\begin{tabular}{|l|c|c|c|c|}
\hline Parameter values: $k_{H}=1.5$ & $k_{L}=c_{L}=1$ & $c_{H}=4$ & $\eta=0.5 \quad b=0.07$ & $y=0.0025$ \\
\hline & $\begin{array}{l}\text { No } \\
\text { Labeling }\end{array}$ & $\begin{array}{l}\text { Voluntary } \\
\text { COOL }\end{array}$ & $\begin{array}{l}\text { Partial } \\
\text { MCOOL }\end{array}$ & $\begin{array}{l}\text { Total } \\
\text { MCOOL }\end{array}$ \\
\hline $\begin{array}{l}\text { Expected Consumer } \\
\text { Surplus }\end{array}$ & 0.130 & 0.150 & 0.156 & 0.113 \\
\hline $\begin{array}{l}\text { Real Consumer } \\
\text { Surplus }\end{array}$ & -0.005 & 0.104 & 0.076 & 0.113 \\
\hline Producer Surplus & 0.130 & 0.171 & 0.156 & 0.113 \\
\hline Total Welfare & 0.125 & 0.275 & 0.232 & 0.225 \\
\hline
\end{tabular}

Table 2: Equilibrium price and quantity comparisons for fixed parameter values.

\begin{tabular}{|l|c|c|c|l|c|}
\hline \multicolumn{1}{|l|}{ Parameter values: $k_{H}=1.5$} & $k_{L}=c_{L}=1$ & $c_{H}=4 \quad \eta=0.5 \quad b=0.07$ & $y=0.0025$ \\
\hline Sector & $\begin{array}{l}\text { Equilibrium } \\
\text { price and } \\
\text { quantity }\end{array}$ & $\begin{array}{c}\text { No } \\
\text { Labeling }\end{array}$ & $\begin{array}{l}\text { Voluntary } \\
\text { COOL }\end{array}$ & $\begin{array}{l}\text { Partial } \\
\text { MCOOL }\end{array}$ & $\begin{array}{l}\text { Total } \\
\text { MCOOL }\end{array}$ \\
\cline { 2 - 6 } Retail & $p_{H}, q_{H}$ & N/A & $0.999,0.170$ & $1.103,0.208$ & $1.119,0.107$ \\
\cline { 2 - 6 } & $p_{L}, q_{L}$ & N/A & N/A & $0.707,0.085$ & $0.673,0.220$ \\
\cline { 2 - 6 } & $\bar{p}, q_{L}$ & $0.847,0.323$ & $0.792,0.197$ & N/A & N/A \\
\hline \multirow{3}{*}{ Foodservice } & $p_{H}, q_{H}$ & N/A & N/A & N/A & $1.119,0.107$ \\
\cline { 2 - 6 } & $p_{L}, q_{L}$ & N/A & N/A & N/A & $0.673,0.220$ \\
\cline { 2 - 6 } & $\bar{p}, q_{L}$ & $0.847,0.323$ & $0.792,0.366$ & $0.743,0.405$ & N/A \\
\hline
\end{tabular}

Note: N/A refers to not applicable 
Figure 1: Market scenarios for COOL implementation

\section{a. Pre-MCOOL: No Labeling}
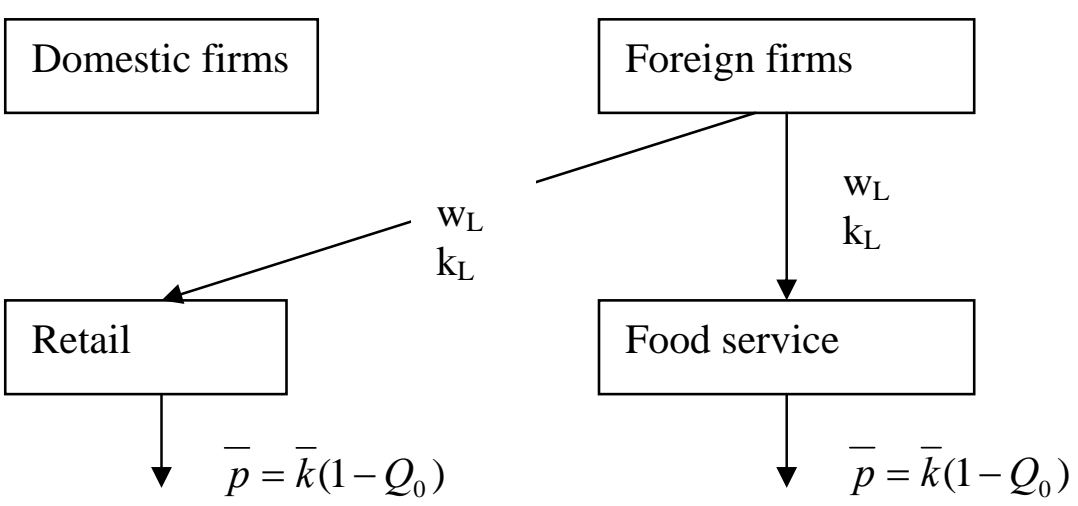

\section{b. Pre-MCOOL: Voluntary COOL Labeling at Retail}
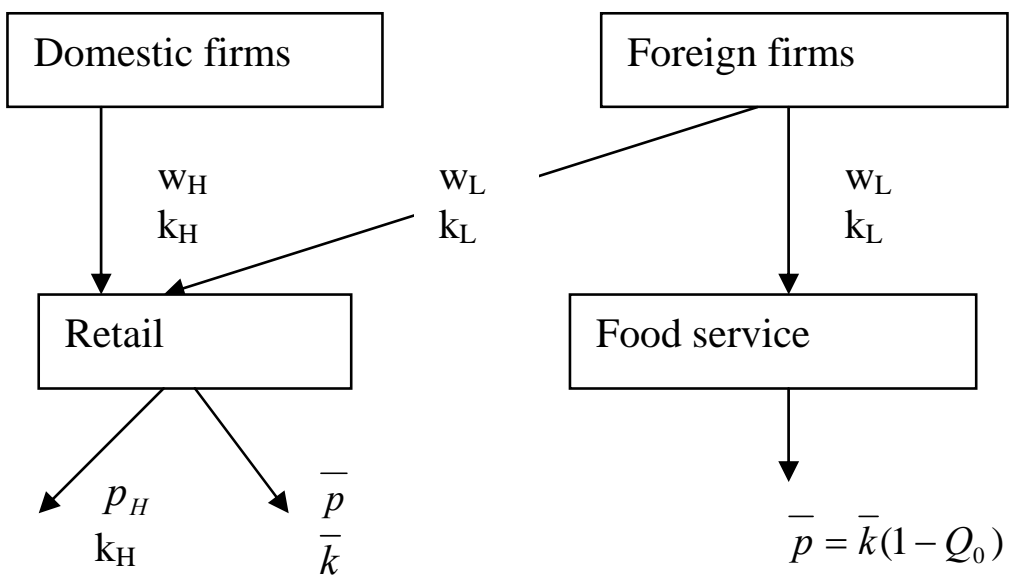

\section{c. Partial MCOOL Implementation at Retail}
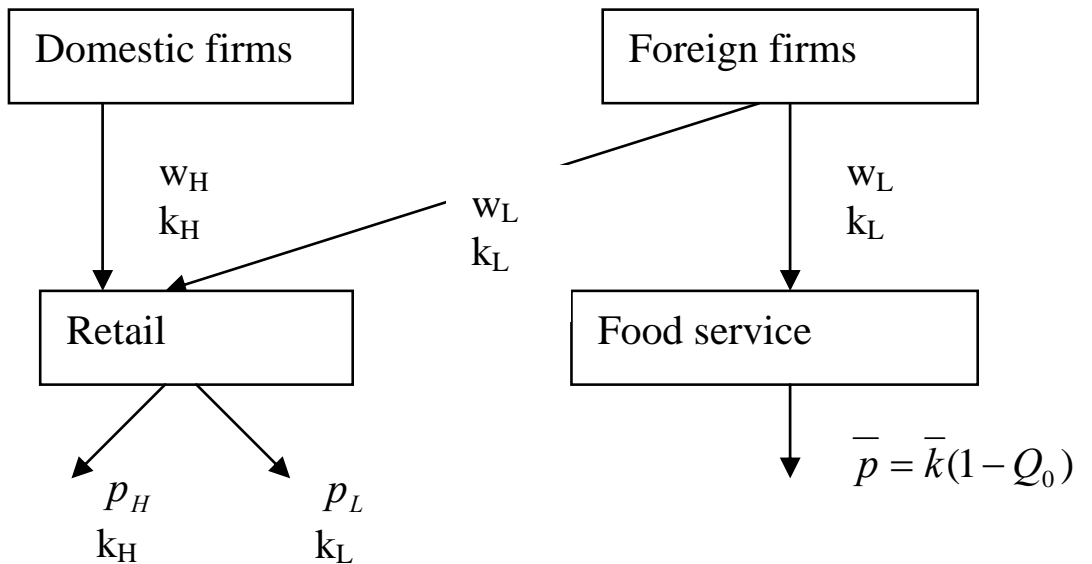

d. Total MCOOL Implementation at Retail \& Foodservice

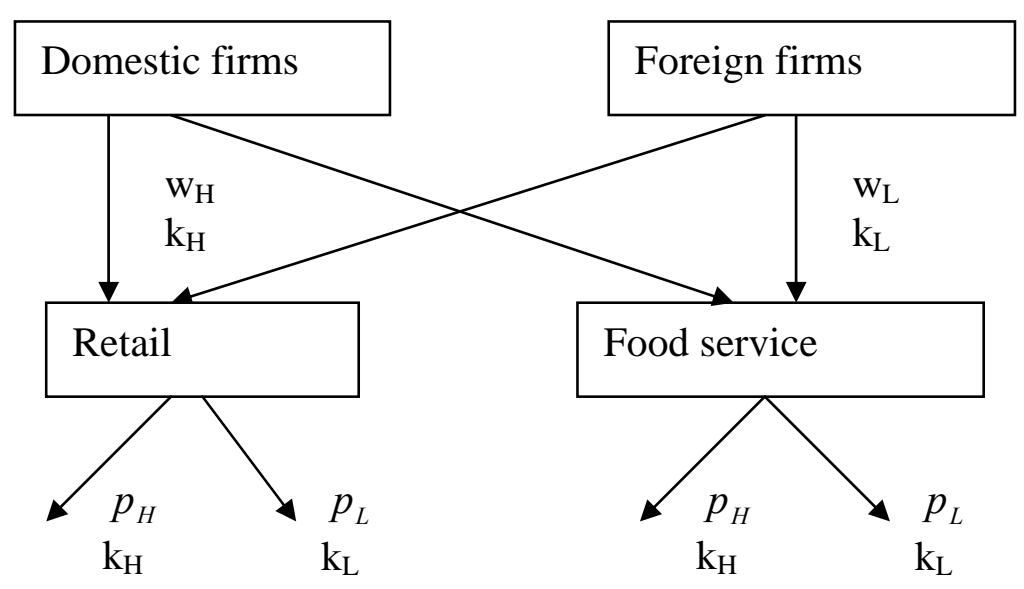


Figure 2: Diversion under Partial MCOOL

a. Pre-MCOOL: No Labeling

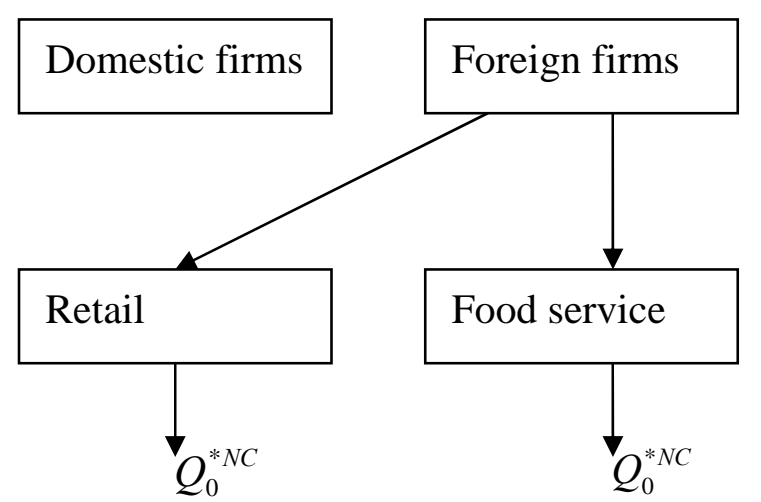

b. Post-MCOOL: Partial MCOOL Implementation

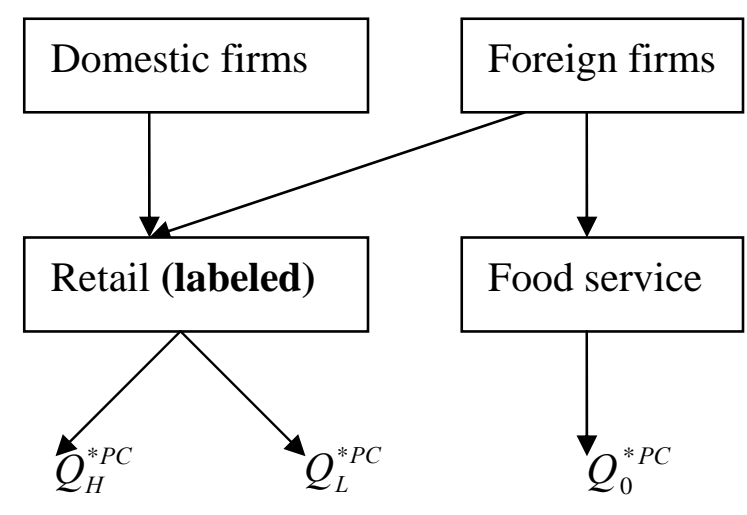

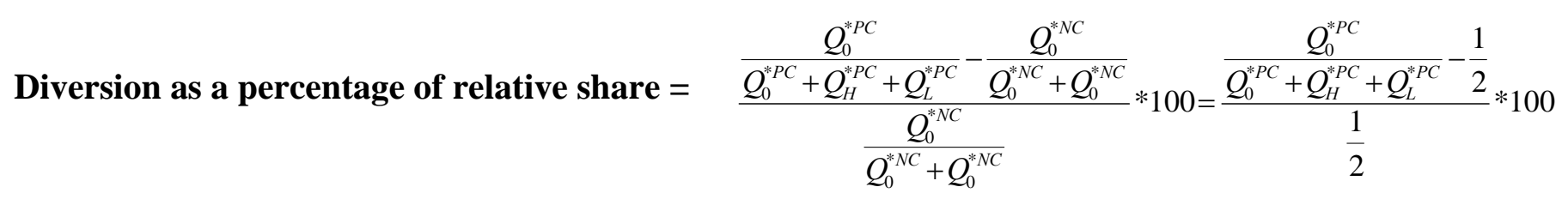


Figure 3: Effect of increasing quality differences between domestic and foreign seafood on Diversion percentage under partial MCOOL $\left(\eta=0.5, c_{H}=4\right)$

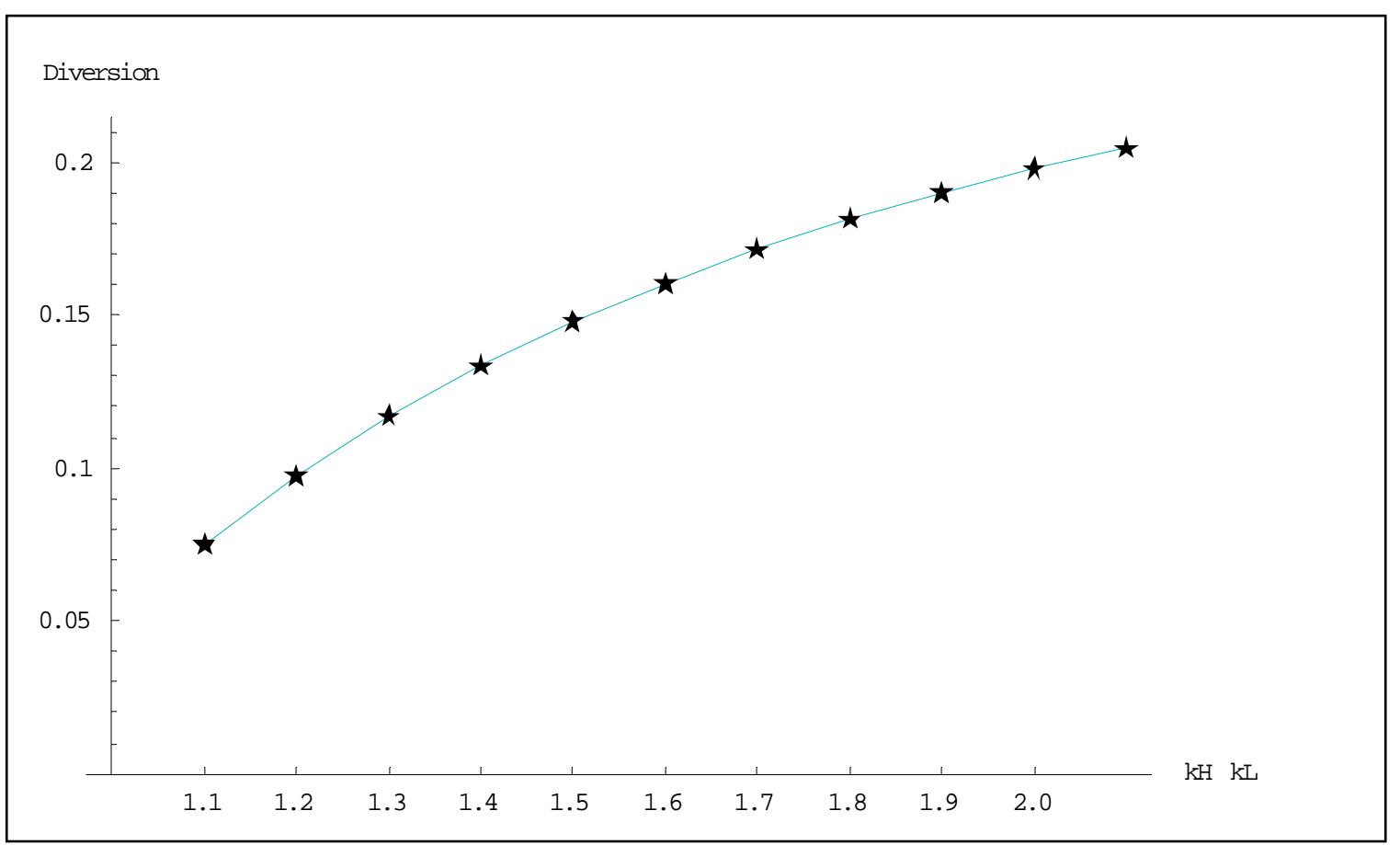

Figure 4: Effect of increasing quality differences between domestic and foreign seafood on Expected consumer surplus ( $\left.\eta=0.5, c_{H}=4\right)$

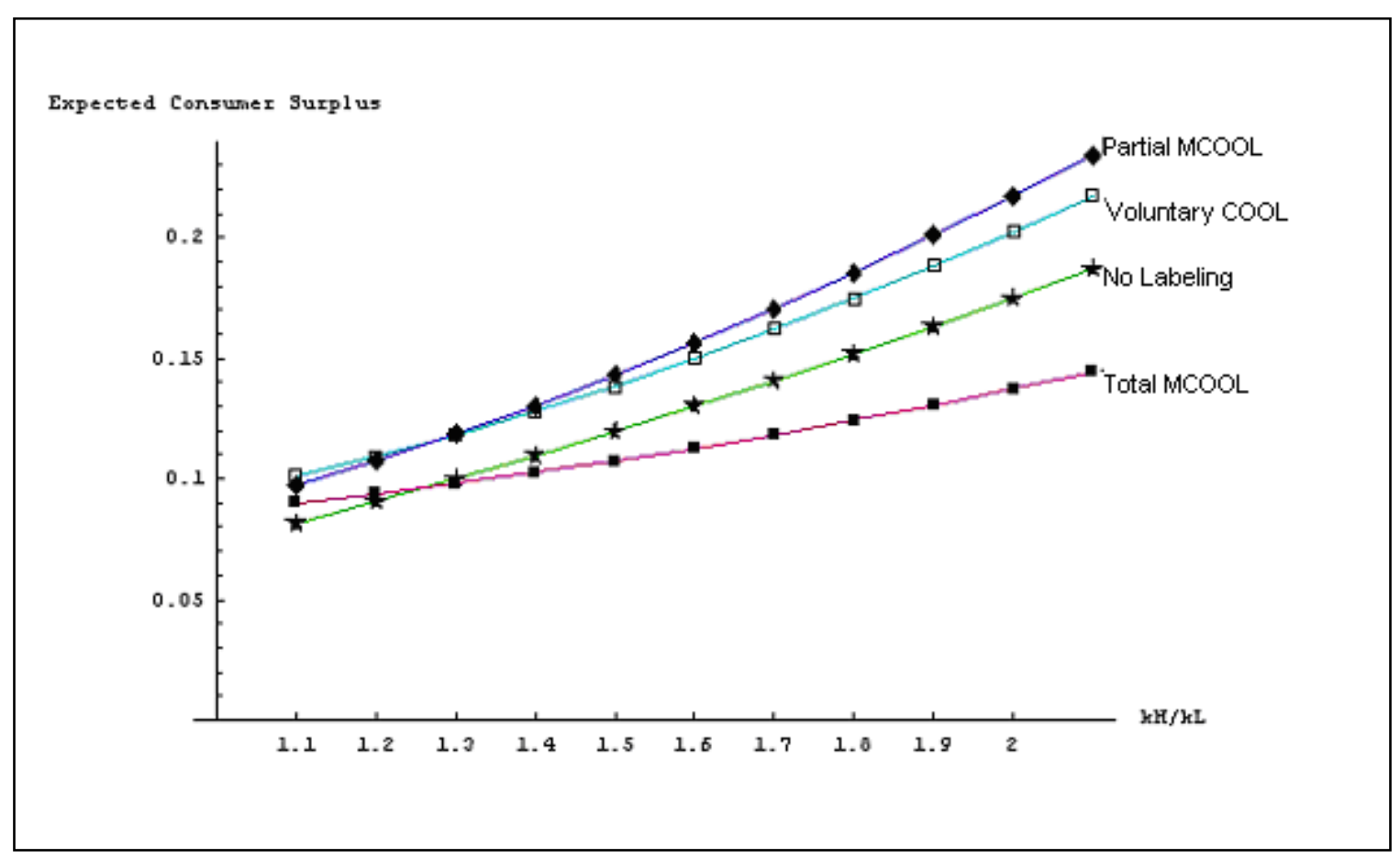


Figure 5: Effect of increasing quality differences between domestic and foreign seafood on Real consumer surplus ( $\left.\eta=0.5, c_{H}=4\right)$

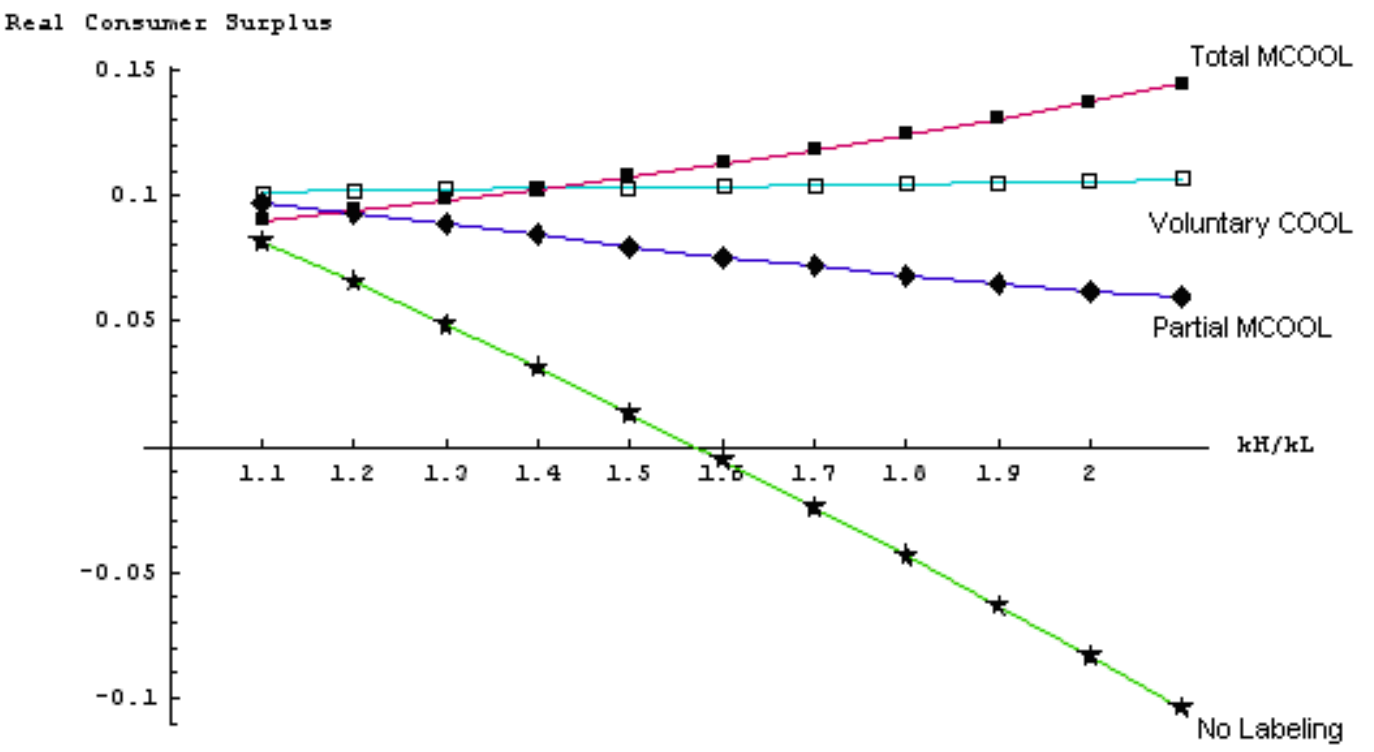

Figure 6: Effect of increasing quality differences between domestic and foreign seafood on Profit ( $\left.\eta=0.5, c_{H}=4\right)$

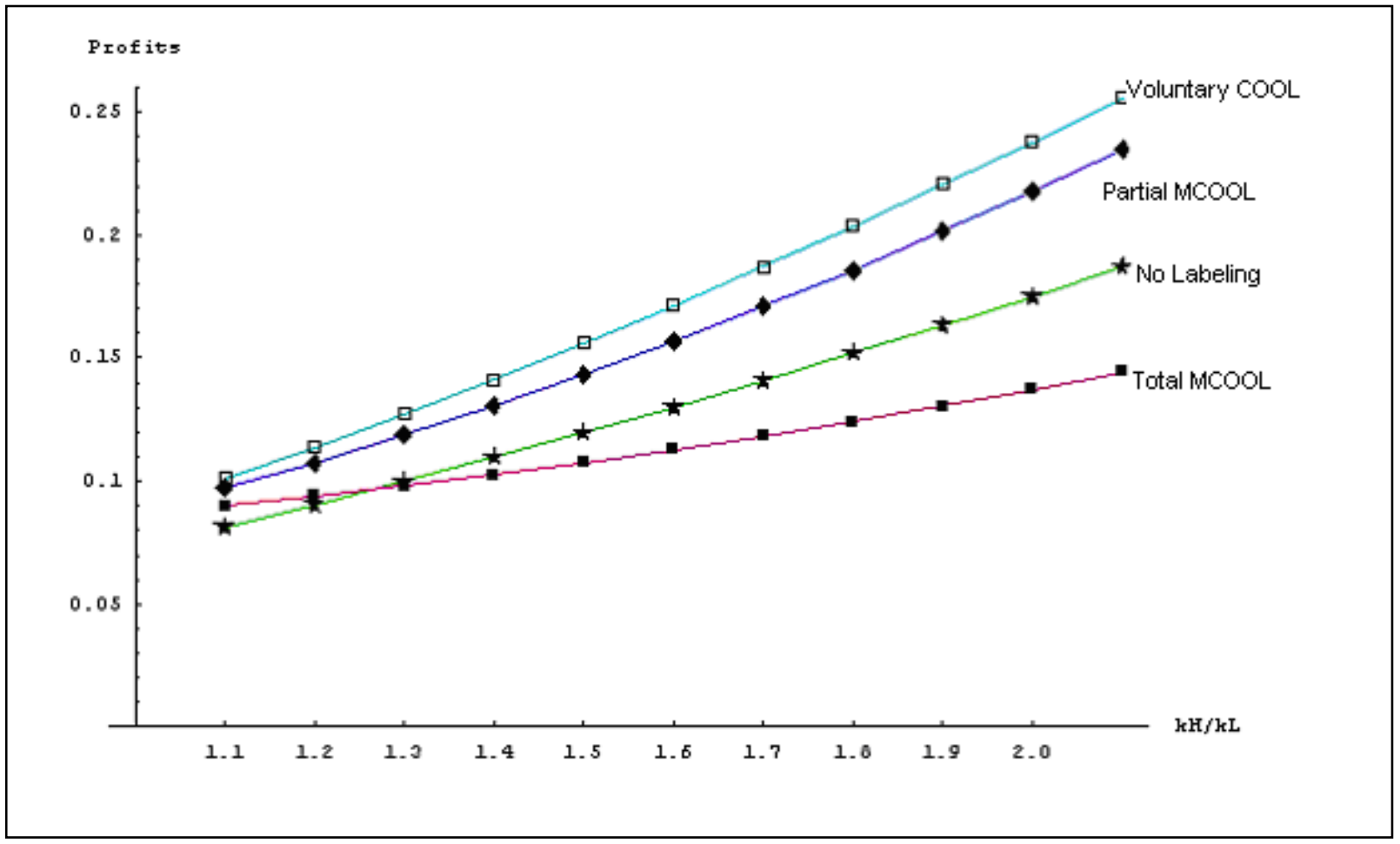


Figure 7a: Effect of varying labeling costs on Profits with $k_{H}=1.1, \eta=0.5$, and $c_{H}=4$

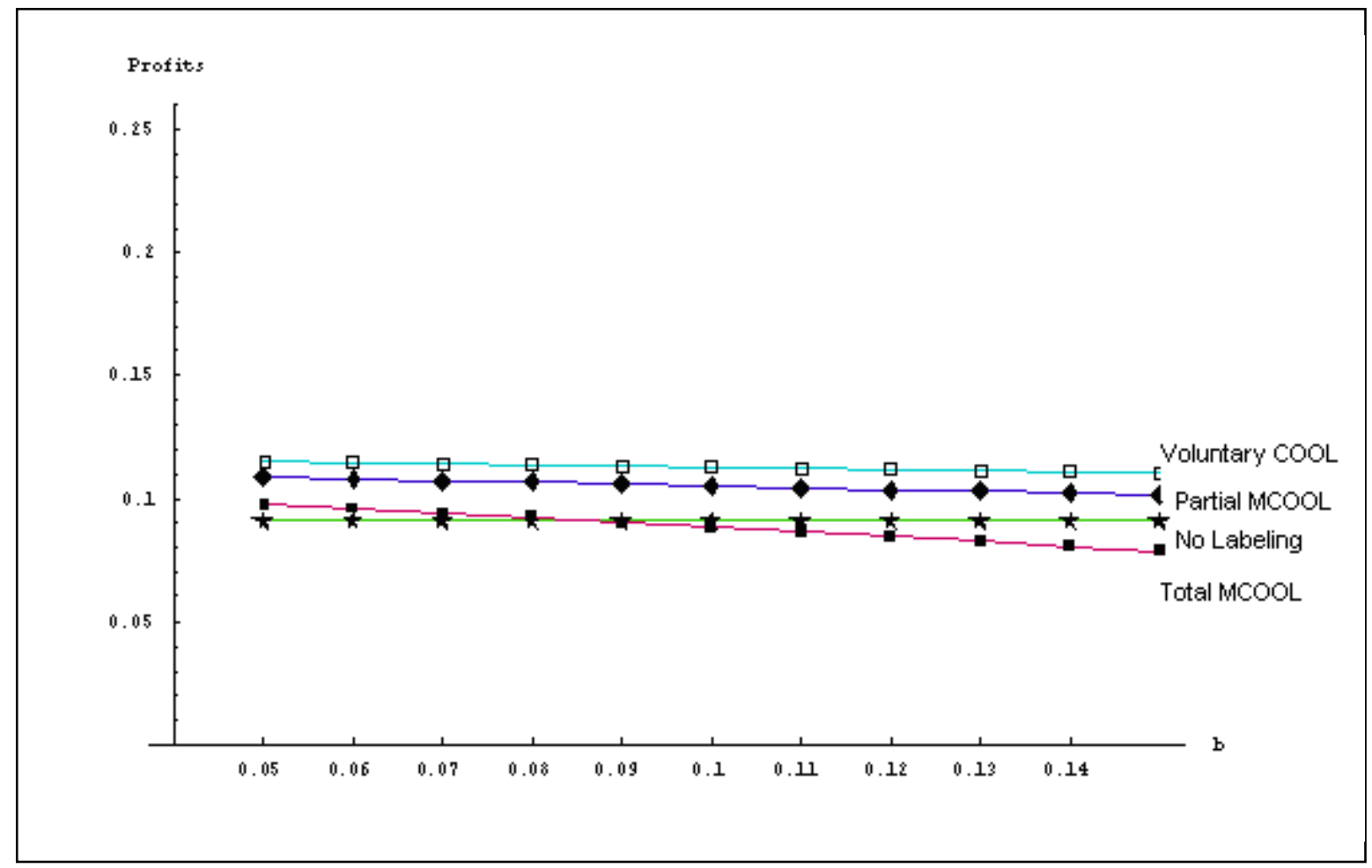

Figure 7b: Effect of varying labeling costs on Profits with $k_{H}=2, \eta=0.5$, and $c_{H}=4$

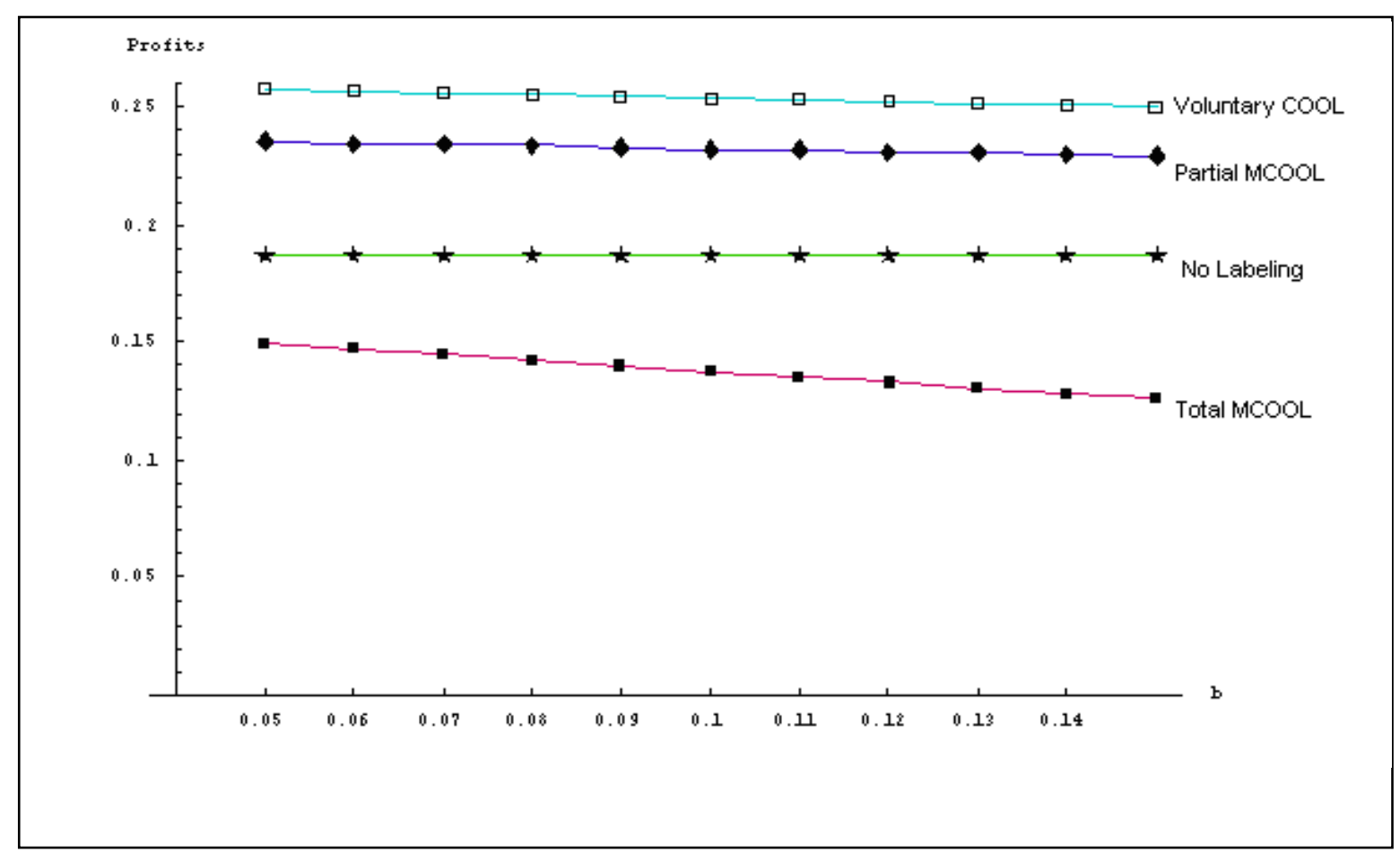


Figure 8: Effect of increasing quality differences between domestic and foreign seafood on Total welfare $\left(\eta=0.5, c_{H}=4\right)$

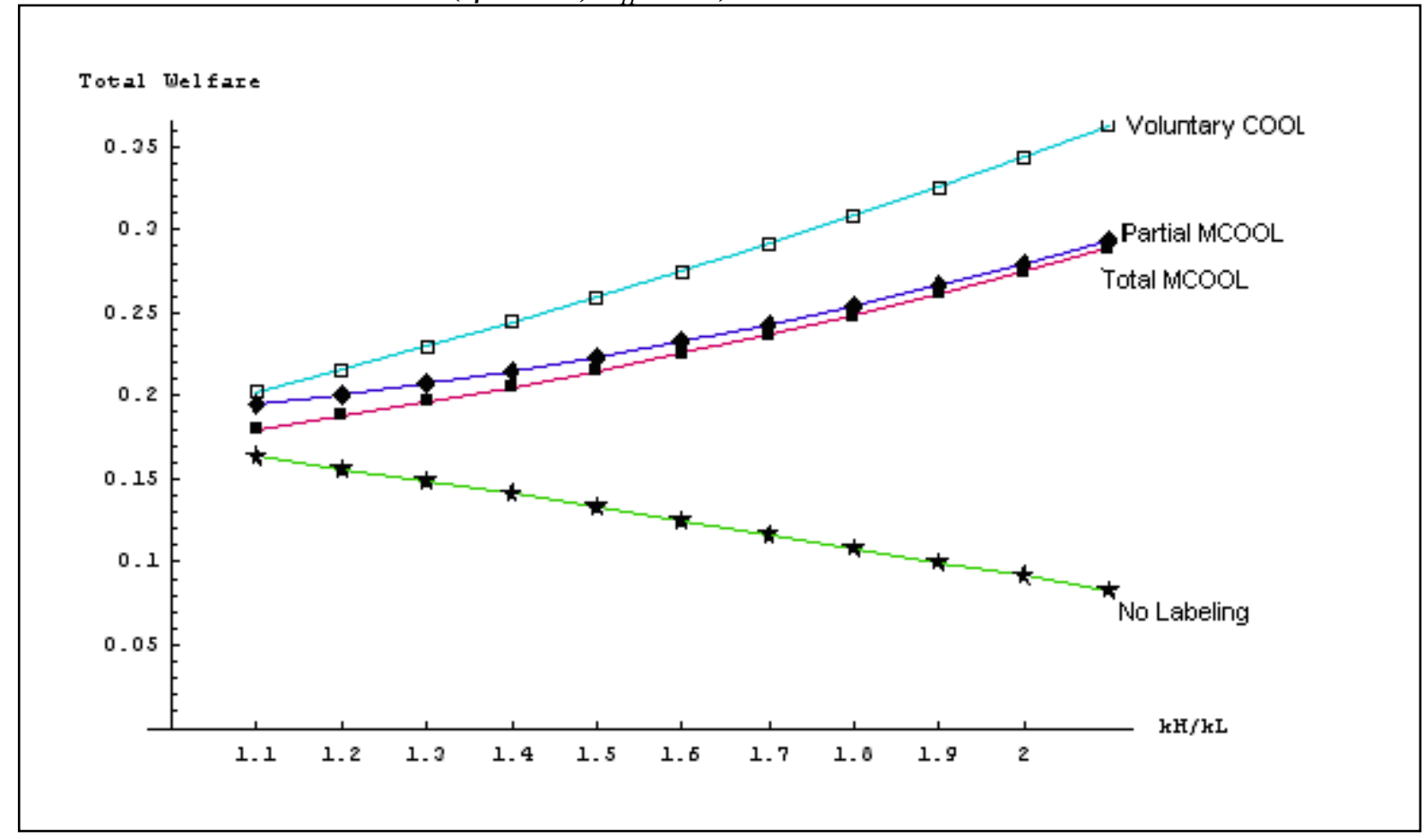

